\title{
High glass forming ability correlated with microstructure and hydrogen storage properties of a $\mathrm{Mg}-\mathrm{Cu}-\mathrm{Ag}-\mathrm{Y}$ glass
}

\author{
Á. Révész ${ }^{1, *}$, Á. Kis-Tóth ${ }^{1}$, L.K. Varga ${ }^{2}$, J.L. Lábár ${ }^{3}$, T. Spassov ${ }^{4}$
}

${ }^{1}$ Department of Materials Physics, Eötvös University, Budapest, H-1518, P.O.B. 32, Budapest, Hungary

${ }^{2}$ Research Institute for Solid state Physics and Optics, Hungarian Academy of Sciences. H-1525 Budapest, P.O.B. 49, Hungary

${ }^{3}$ Institute for Technical Physics and Materials Science, Research Center for Natural Sciences, Hungarian Academy of Sciences, Budapest, Hungary

${ }^{4}$ Department of Chemistry, University of Sofia "St. K1. Ohridski", 1 J. Bourchier str., 1164 Sofia, Bulgaria

\begin{abstract}
Thermal characterization of an as-cast $\mathrm{Mg}_{54} \mathrm{Cu}_{28} \mathrm{Ag}_{7} \mathrm{Y}_{11}$ bulk metallic glass revealed that this alloy exhibits excellent glass forming ability. High-resolution X-ray diffraction study and transmission electron microscopy show that heating and isothermal annealing treatment results in the nucleation of nanocrystals of several phases. The average size of these nanocrystals $(\sim 15-20 \mathrm{~nm})$ only slightly varies with prolonged annealing, only their volume fraction increases. High-pressure calorimetry experiments indicate that the as-cast fully amorphous alloy exhibits the largest enthalpy of hydrogen desorption, compared to partially
\end{abstract}

${ }^{1}$ Corresponding author. Tel.: +36-1-372-2823; fax: +36-1-372-2811.

E-mail address: reveszadam@ludens.elte.hu (Á. Révész) 
and fully crystallized states. Since the fully crystallized alloy does not desorb hydrogen, it is assumed that hydrogen storage capacity correlates only with the crystalline volume fraction of the partially crystallized $\mathrm{Mg}_{54} \mathrm{Cu}_{28} \mathrm{Ag}_{7} \mathrm{Y}_{11} \mathrm{BMG}$ and additional parameters (crystalline phase selection, crystallite size, average matrix concentration) do not play a significant role.

Keywords: H-storage; bulk metallic glass; amorphous, Mg-based; glass forming ability 


\section{Introduction}

The wish of wide-spread application of renewable green energy is in the focus of research and industry, albeit these sources, i.e. sun, wave and wind are irregularly distributed in time and space, therefore efficient energy storage is of great importance. Due to its physical and chemical advantageous properties, hydrogen could be an ideal promising energy carrier in the next decades [1]. In order to rationalize the hydrogen economy, developing cost-effective, efficient and safe storage technologies are the main issues. The use of hydrogen can generate several times more energy per mass compared to the traditional energy carriers, yet it happens as a gas at ambient conditions. The main drawback of recent industrial application is the lack of effective storage [1].

Storing hydrogen in solid-state appears to be a method with appropriate potential storage capacity to realize the hydrogen economy [2]. Recent approaches have focused on metallic hydrides, since they possess high volumetric and gravimetric hydrogen storage performance. Among them $\mathrm{MgH}_{2}$ is particularly considered as one of the most attractive hydrogen absorbing materials, since it exhibits outstanding storage capacity (7.6 wt.\%), lightweight, low environmental impact, high abundancy and low cost [2]. To improve the storage properties, kinetics and temperature of desorption of magnesium, nano-sized $\mathrm{Mg}$ and $\mathrm{Mg}$ based metallic compound powders have been synthesized by ball milling (BM) intensively [38], however, all attempts to reduce the temperature of dehydrogenation below 150 degrees have failed until now. Nevertheless, other non-equilibrium techniques, such as rapid quenching (RQ) enables the formation of highly metastable structures. As was demonstrated by Zhang et al., the cooling rate as well as the $\mathrm{Cu} / \mathrm{Ni}$ ratio significantly alters the dehydrogenation behaviour of RQ crystalline $\mathrm{Mg}-\mathrm{Ni}-\mathrm{Cu}$ alloys [9-10]. It was found that the substitution of $\mathrm{Ni}$ by $\mathrm{Cu}$ yields a notable increase in the hydrogen diffusion coefficient [11]. Bendersky et al. demonstrated that $\mathrm{Mg}-\mathrm{Ni}$ alloys produced by the combination of RQ and 
subsequent BM posses very fast $\mathrm{H}$-absorption kinetics [12]. The proper addition of rear earth ( $\mathrm{Y}, \mathrm{La}, \mathrm{Ce}$ ) to $\mathrm{Mg}$ and $\mathrm{Mg}-\mathrm{Ni}$ alloys by the RQ technique facilitates even more disordered systems, i.e. partially crystalline [13-14] or monolithic amorphous alloys [15-18] with further improved storage properties.

Unfortunately, the remarkably high cooling rate that is required to achieve a fully amorphous structure by RQ, causes the limitation to small sample dimensions. Nevertheless, the past two decades have demonstrated that bulk glassy alloys of particular composition can directly be cast from the liquid state. So far, numerous classes of bulk metallic glasses (BMGs) with sample size ranging from few millimetres to couple of centimetres have been discovered [19]. Due to their high glass forming ability (GFA), the critical cooling rate to achieve a fully glassy structure can be as low as $0.1 \mathrm{Kmin}^{-1}$ [20]. Among BMGs, magnesium-based systems are specifically interesting because of high strength, low cost and extraordinary high GFA [21-23]. The first series of Mg-based BMG discovered in 1992 by Inoue et al. was $\mathrm{Mg}_{90-}$ ${ }_{x} \mathrm{Cu}_{\mathrm{x}} \mathrm{Y}_{10}$, reaching a maximum sample diameter of $7 \mathrm{~mm}$ at the $\mathrm{Mg}_{65} \mathrm{Cu}_{25} \mathrm{Y}_{10}$ concentration [21]. It has recently been found that the GFA of $\mathrm{Mg}-\mathrm{Cu}-\mathrm{Y}$ BMGs can be improved by the partial substitution of $\mathrm{Cu}$ by transition metals, such as $\mathrm{Ag}$ [24], because of the large atomic size mismatch between $\mathrm{Ag}$ and the other constituents, the large negative heat of mixing in Ag$\mathrm{Mg}$ and $\mathrm{Ag}-\mathrm{Y}$ and the significant reduction in crystal growth rate [25]. At the same time, the thermal stability of these alloys slightly decreases with increasing Ag-content [25]. Recently Ma and co-workers have systematically monitored the variation of sample diameter in the three-dimensional composition space for the $\mathrm{Mg}-\mathrm{Cu}-\mathrm{Ag}-\mathrm{Y}$ and $\mathrm{Mg}-\mathrm{Cu}-\mathrm{Ag}-\mathrm{Gd}$ systems, showing the maximum value of $16 \mathrm{~mm}$ and $25 \mathrm{~mm}$ at $\mathrm{Mg}_{54} \mathrm{Cu}_{28} \mathrm{Ag}_{7} \mathrm{Y}_{11}$ and $\mathrm{Mg}_{54} \mathrm{Cu}_{26.5} \mathrm{Ag}_{8.5} \mathrm{Gd}_{11}$ concentrations, respectively [26]. As a consequence, Mg-based BMGs are excellent candidates to produce new light alloys for structural and functional applications with high applicability of near net shaping. 
In the present paper, we demonstrate a comprehensive study on the GFA, thermal stability and crystallization kinetics of an amorphous $\mathrm{Mg}-\mathrm{Cu}-\mathrm{Ag}-\mathrm{Y}$ bulk metallic glass. In addition, we present hydrogen desorption experiments on the fully amorphous and partially crystallized samples.

\section{Experimental}

\subsection{Sample preparation}

An alloy with a nominal composition of $\mathrm{Mg}_{54} \mathrm{Cu}_{28} \mathrm{Ag}_{7} \mathrm{Y}_{11}$ was characterized in the present study. Elemental pieces of $\mathrm{Mg}, \mathrm{Ag}, \mathrm{Cu}$ and $\mathrm{Y}$ (99.9 wt.\% purity) were used as starting materials. As a first step, an intermediate binary $\mathrm{Cu}-\mathrm{Y}$ alloy was prepared by induction melting in a Ti-gettered $\mathrm{Ar}$ atmosphere. Then this alloy was melted together with $\mathrm{Mg}$ and $\mathrm{Ag}$ in a water-cooled copper mould to obtain a master alloy. The master alloy was re-melted again for five times to ensure compositional homogeneity. As-cast cylinders with a diameter of $3 \mathrm{~mm}$ were obtained by injection of the molten liquid into a copper mould having a mass of two order of magnitude larger than the mass of the sample.

\subsection{Characterization of microstructure}

High resolution X-ray diffraction measurements applying monochromatic $\mathrm{Cu} \mathrm{K \alpha}$ radiation were carried out on a double crystal diffractometer with negligible instrumental broadening. The diffractometer was equipped with a fine focus rotating copper anode (Nonius, FR 591) operating at $45 \mathrm{kV}$ and $80 \mathrm{~mA}$. The spot size of the X-ray beam on the specimen $(100 \times 300$

$\mu \mathrm{m}^{2}$ ) enables high spatial resolution. 2-dimensional diffraction patterns registered by FUJI Imaging Plate (BAS MS2025) were integrated after spatial distortion correction. Coherent 
grain size of the partially or fully crystallized samples has been evaluated from the Scherrer formula [27]. Phase analysis has been carried out by the commercial PCPDFWIN software package.

Morphology studies of the as-cast alloy were carried out on a FEI QUANTA 3D dual beam scanning electron microscope (SEM) in back-scattered electron (BSE) mode on the surface of a $10 \times 10 \mu \mathrm{m}^{2}$ notch sputtered by a focused ion-beam (FIB) setup operating at $30 \mathrm{kV}$ with a current of $7 \mathrm{nA}$. Patterns were sputtered by a liquid gallium source. Local composition was quantitatively determined by energy dispersive X-ray (EDX) analysis with a relative accuracy of $1 \%$.

Some selected partially crystallized samples have been examined by transmission electron microscopy (TEM). The TEM lamellae were prepared from a piece of bulk material started by mechanical thinning down to $50 \mu \mathrm{m}$, followed by Ar-ion milling till perforation. The initial energy of the Ar-ions of $7 \mathrm{keV}$ was finally reduced in 3 steps ( $3 \mathrm{keV}$ and $1 \mathrm{keV}$ ) to $300 \mathrm{eV}$ for removal of the surface layer caused by the ion bombardment and also remove surface oxide artifact. The samples were cooled by liquid nitrogen during ion milling to prevent transformation of the initial structure. The lamella was immediately inserted into the JEOL 3010 TEM (operated at $300 \mathrm{keV}$ ) to prevent formation of oxide artifact between preparation and examination. Images were recorded with a GATAN Imaging Filter (GIF Tridiem).

\subsection{Thermal characterization}

A power-compensated differential scanning calorimeter (Perkin Elmer DSC) was applied for continuous heating experiments at scan rates of $2.5 \mathrm{Kmin}^{-1}, 5 \mathrm{Kmin}^{-1}, 10 \mathrm{Kmin}^{-1}, 20 \mathrm{Kmin}^{-1}$, $40 \mathrm{Kmin}^{-1}$ and $80 \mathrm{Kmin}^{-1}$. From the shift of the DSC peaks with increasing heating rate, the apparent activation energy of a transformation was determined [28]. The enthalpies of transformation were obtained as the area of the exothermic peaks. Isothermal annealing 
experiments were carried out by heating the sample to the desired temperature at a rate of 100 $\mathrm{Kmin}^{-1}$. The temperature and the enthalpy were calibrated by melting of pure $\mathrm{Al}$ and In. All measurements were carried out in Al sample pans under a protective flowing argon gas.

\subsection{Hydrogen absorption measurements}

High-pressure differential scanning calorimetry (HP-DSC) was applied on a SETARAM Sensys Evo TG-DSC equipment to investigate the hydrogen desorption during annealing of the as-cast and partially crystallized $\mathrm{Mg}_{54} \mathrm{Cu}_{28} \mathrm{Ag}_{7} \mathrm{Y}_{11}$ samples. The specimens were sealed in argon in a pressure cell and transferred to the HP-DSC apparatus. Then Ar was pumped out and the system was flushed by hydrogen $(99.999 \%)$. Before each heating run, the hydrogen pressure was set to a constant pressure of 60 bar in order to achieve full hydrogenation. Subsequently, the hydrogen was pumped out from the apparatus and a linear heating scan at rate of $5 \mathrm{Kmin}^{-1}$ was applied in the $300 \mathrm{~K}-470 \mathrm{~K}$ range.

\section{Results}

\subsection{Continuous heating experiments}

Continuous heating DSC curve obtained at a heating rate of $20 \mathrm{Kmin}^{-1}$ of the as cast $\mathrm{Mg}_{54} \mathrm{Cu}_{28} \mathrm{Ag}_{7} \mathrm{Y}_{11}$ alloy is presented in Fig. 1. A clear endothermic event corresponding to a glass-transition is followed by a supercooled liquid (SCL) region and two exothermic crystallization peaks $\left(\mathrm{T}_{1}, \mathrm{~T}_{2}\right)$. For further analysis of the thermal stability of the glass, additional representative temperatures, i.e the onset $\left(\mathrm{T}_{\mathrm{g}, \mathrm{on}}\right)$ and the end $\left(\mathrm{T}_{\mathrm{g}, \text { end }}\right)$ of the glass transition and the onset of crystallization $\left(\mathrm{T}_{\mathrm{x}, \mathrm{on}}\right)$ were also determined by the intersect method, see the left inset in Fig.1. The width of the SCL range, defined as $\Delta \mathrm{T}_{\mathrm{x}}=\mathrm{T}_{\mathrm{x}, \mathrm{on}}-\mathrm{T}_{\mathrm{g}, \mathrm{on}}$, is usually used to estimate the stability of the liquid against crystallization. For the 
$\mathrm{Mg}_{54} \mathrm{Cu}_{28} \mathrm{Ag}_{7} \mathrm{Y}_{11}$ system the $\Delta \mathrm{T}_{\mathrm{x}}=49 \mathrm{~K}$, in consistent with literature data [22]. The large value of $\Delta \mathrm{T}_{\mathrm{x}}$ is an indicative of the high resistance of the undercooled liquid to crystallization and consequently the nucleation of any primary crystalline phase is retarded. The right inset presents the melting enotherm of the alloy with the solidus $\left(T_{m}=702 K\right)$ and liquidus $\left(T_{1}=729\right.$ K) temperatures. The single sharp endothermic peak could refer to a eutectic concentration of the alloy, however, Ma et al. previously reported that the best BMG forming region in the $\mathrm{Mg}-\mathrm{Cu}-\mathrm{Ag}-\mathrm{Y}$ system (around the $\mathrm{Mg}_{54} \mathrm{Cu}_{28} \mathrm{Ag}_{7} \mathrm{Y}_{11}$ concentration) is bit off-centered from the eutectic composition [26]. With the available data, additional GFA parameters, such as reduced glass transition temperature $\left(\mathrm{T}_{\mathrm{rg}}=\mathrm{T}_{\mathrm{g}, \mathrm{on}} / \mathrm{T}_{1}\right)$ and $\gamma$ parameter $\left(\gamma=\mathrm{T}_{\mathrm{x}, \mathrm{on}} /\left(\mathrm{T}_{\mathrm{g}, \mathrm{on}}+\mathrm{T}_{1}\right)\right)$ can also be determined. The characteristic temperatures of the main transformations and the GFA parameters are listed in Table I. Both $\mathrm{T}_{\mathrm{rg}}=0.592$ and $\gamma=0.414$ refer to an excellent glass former $[23,29]$. At the glass transition, the thermogram exhibits the usual endothermic event $\left(\Delta \mathrm{H}_{\mathrm{g}}\right)$ which corresponds to a structural relaxation. The enthalpy of crystallization was obtained as the area of the first and second exothermic peak $\left(\Delta \mathrm{H}_{1}\right.$ and $\left.\Delta \mathrm{H}_{2}\right)$. It is noted that $\mathrm{Ag}$ addition to $\mathrm{Mg}-\mathrm{Cu}-\mathrm{Y}$ alloys usually results in a more complex crystallization sequence instead of a single step transformation [29], in accordance with the wide SCL region.

The activation energy $\left(E_{a}\right)$ and the frequency factor $(Z)$ corresponding to glass transition and crystallization events can be determined from the Kissinger analysis [28]. For this purpose, additional continuous heating DSC runs were performed at different heating rates $(\beta)$, ranging from $2.5 \mathrm{Kmin}^{-1}$ to $80 \mathrm{Kmin}^{-1}$ (Fig. 2). At all heating rates these curves present very similar behavior, however, higher heating rate results in higher characteristic temperatures (see Table I). The estimated average values of $\Delta \mathrm{H}_{\mathrm{g}},=-16 \mathrm{Jg}^{-1}, \Delta \mathrm{H}_{1}=47 \mathrm{Jg}^{-1}$ and $\Delta \mathrm{H}_{2}=10 \mathrm{Jg}^{-1}$ show little scatter with the heating rate. The dependence of peak temperatures on the heating rate can be given by the 


$$
\frac{\beta}{T_{i}^{2}}=\frac{Z_{i} R}{E_{a, i}} \exp \left(\frac{-E_{a, i}}{R T_{i}}\right)
$$

equation, where $R$ is the gas constant and the index $i$ refers to $g$, lor 2 . The $\ln \left(\beta / T_{i}^{2}\right)$ vs. $T_{i}^{-1}$ plot enables $E_{a, i}$ for each step from the slope of the fitted straight lines (see the inset in Fig. 2). The calculated values $\left(E_{a, g}=161 \mathrm{kJmol}^{-1}, E_{\mathrm{a}, 1}=107 \mathrm{kJmol}^{-1}\right.$ and $\left.\mathrm{E}_{\mathrm{a}, 2}=104 \mathrm{kJmol}^{-1}\right)$, in agreement with literature data [22], refer to high thermal stability and indicate that the crystallization takes place through a nucleation and growth mechanism. The frequency factor, which measures the probability that an atom with energy $E_{a}$ joins to an existing nucleus, can be determined from the intercept of the fitted line with the ordinate. For the $\mathrm{Mg}_{54} \mathrm{Cu}_{28} \mathrm{Ag}_{7} \mathrm{Y}_{11}$ alloy the obtained values $\left(\mathrm{Z}_{1}=8 * 10^{22} \mathrm{~s}^{-1}\right.$ and $\left.\mathrm{Z}_{2}=3 * 10^{19} \mathrm{~s}^{-1}\right)$ are considerably lower than for Fe-based BMGs [30,31], indicating again the high GFA and resistance against crystallization. The deeper understanding of GFA of metallic glasses can be achieved through a correlation with fragility properties of the SCL [32]. Since glass transition is a kinetically modified thermodynamic phase transformation, $\mathrm{T}_{\mathrm{g}, \mathrm{on}}$ varies with the heating rate. According to the Vogel-Fulcher-Tammann (VFT) approach, the variation of $\mathrm{T}_{\mathrm{g}, \mathrm{on}}$ as a function of $\beta$ can be ascribed as [33]

$$
\beta=B \exp \left(\frac{A}{T_{g}^{0}-T_{g, \text { on }}}\right),
$$

or

$$
\mathrm{T}_{\mathrm{g}, \text { on }}=\mathrm{T}_{\mathrm{g}}{ }^{0}+\left(\frac{\mathrm{A}}{\ln (\mathrm{B} / \beta)}\right) \text {, }
$$


where $\mathrm{A}$ and $\mathrm{B}$ are constants and $\mathrm{T}_{\mathrm{g}}{ }^{\circ}$ is the VFT temperature, usually approximated as the onset of the glass transition in the limit of infinitely slow cooling rate. The convincing fit of $\mathrm{T}_{\mathrm{g}, \mathrm{on}}$ Vs. $\beta$ plot provides the VFT parameters, see Fig. 3. Undoubtedly, the data points deviate from a straight line, indicating a more VFT-like dependence of the calorimetric glass transition, rather than an Arhenius one [33]. Such non-linear behavior implies that the $\mathrm{Mg}_{54} \mathrm{Cu}_{28} \mathrm{Ag}_{7} \mathrm{Y}_{11}$ system exhibits an internal time scale of glass transition, which is proportional to the parameter $\mathrm{B}$ [33]. Noteworthy the large value of $\mathrm{B}(\ln \mathrm{B}=6.35 \mathrm{~K} / \mathrm{s})$ indicates that a long waiting time is necessary to get the system achieving an ideal state. The inset of Fig. 3 shows the width of the glass transition, $\Delta T_{g}=T_{g, \text { end }}-T_{g, \text { on }}$ as a function of the logarithm of the heating rate. Evidently, $\Delta \mathrm{T}_{\mathrm{g}}$ obeys a clear linear behavior over the whole experimental range. As a remark, $\Delta \mathrm{T}_{\mathrm{g}}$ approaches zero at a critical heating rate $\left(\beta_{\text {crit }}=1.2^{*} 10^{-}\right.$ ${ }^{3} \mathrm{Kmin}^{-1}$ ), below which the glass transition becomes independent of the time scale [33]. At this point $\mathrm{T}_{\mathrm{g}, \text { on }}$ also approaches $\mathrm{T}_{\mathrm{g}}{ }^{0}$ since kinetic effects have no more effect on the glass transition. The fragility parameter $(\mathrm{m})$ of the glass, which is equal to the steepness of the viscosity at the glass transition, can be given by the following equation [34]

$$
\mathrm{m}=\frac{\mathrm{A}}{\left(1-\mathrm{T}_{\mathrm{g}}^{0} / \mathrm{T}_{\mathrm{g}, \text { on }}\right)^{2} \mathrm{~T}_{\mathrm{g}, \text { on }} \ln 10}
$$

The calculated fragility parameter is $\mathrm{m}=38$ for the present composition, which in coincidence with that of $\mathrm{Mg}_{59.5} \mathrm{Cu}_{22.9} \mathrm{Ag}_{6.6} \mathrm{Gd}_{11}$ [32]. According to Angell's classification, such $\mathrm{m}$ value corresponds to an intermediate category of glass forming liquids, nevertheless it is much closer to the strong limit $(m \sim 16)$ than to the fragile limit $(m>100)$ of metallic glasses [35]. Usually, the addition of $\mathrm{Ag}$ to $\mathrm{Mg}$-based and $\mathrm{Cu}-\mathrm{Zr}$ BMGs makes the SCL stronger resulting in the enhancement of GFA $[32,36]$. BMGs of low critical cooling rates exhibit relative small 
fragility parameters in the range of 30-40 [34]. As was demonstrated by Battezzati et al. the reduced width of glass transition $\left(\Delta \mathrm{T}_{\mathrm{g}} / \mathrm{T}_{\mathrm{g}, \text { on }}\right)$ correlates with the inverse of the fragility parameter, i.e. $\Delta \mathrm{T}_{\mathrm{g}} / \mathrm{T}_{\mathrm{g}, \mathrm{on}}=2 * \mathrm{~m}^{-1}$ [37]. Accordingly, the estimated values for the $\mathrm{Mg}_{54} \mathrm{Cu}_{28} \mathrm{Ag}_{7} \mathrm{Y}_{11}$ alloy is $\mathrm{m}=39$, at a heating rate $\beta=20 \mathrm{Kmin}^{-1}$, in line with the above kinetic approach.

The microstructural changes of the $\mathrm{Mg}_{54} \mathrm{Cu}_{28} \mathrm{Ag}_{7} \mathrm{Y}_{11} \mathrm{BMG}$ associated with the linear heating experiments have been characterized by X-ray diffraction. Figure 4 presents the XRD patterns of the as-cast specimen, indicating broad and symmetric halos around $2 \Theta=38$ deg and $2 \Theta=65$ deg which is typical for a "X-ray amorphous" structure. The diffractogram corresponding to the first (lin 518K) transformation reveals the crystallization of several compound phases, i.e. orthorhombic $\mathrm{Mg}_{2} \mathrm{Cu}$ (JCPDS 02-1315, a=0.527 nm, b=0.905 nm, c=1.821 nm), orthorhombic $\mathrm{Cu}_{2} \mathrm{Y}$ (JCPDS 22-0255, a=0.431 nm, b=0.680 nm, c=0.732 nm), cubic MgY (JCPDS 18-0784, a=0.379 nm) and a possible minor traces of $\operatorname{AgMg}_{3}(\mathrm{JCPDS} 01-1170)$. The Bragg peaks of the crystalline phases are superimposed on a faint residual halo, indicating the amorphous component is still present at this stage. For the two major phases, the average crystallite size was about $17 \pm 2 \mathrm{~nm}$. The final microstructure developed after the $T_{2}$ crystallization peak (lin 620K) consists of the similar $\mathrm{Mg}_{2} \mathrm{Cu}, \mathrm{Cu}_{2} \mathrm{Y}, \mathrm{MgY}$ and $\mathrm{AgMg}_{3}$ phases with a complete vanish of the amorphous halo. At the same time, the Bragg-peaks become more intense and narrower corresponding to a mean crystallite size of $20 \pm 3 \mathrm{~nm}$. In accordance with the results of Soubeyroux et al [29], the second thermal event includes only a moderate grain growth.

Figure 5 illustrates a typical SEM-FIB image taken from the inner surface of the ion-milled notch of the as-cast alloy. The composition of the matrix determined by the EDX analysis at several positions is equal to the nominal composition of the alloy within the experimental 
error. The contrastless feature corresponds to a monolithic structure, no evidence of phase separation is observed.

\subsection{Isothermal experiments}

Isothermal annealing of the as-cast amorphous alloy was carried out at several temperatures ( $\left.\mathrm{T}_{\text {iso }}\right)$ in the range of $450 \mathrm{~K}-460 \mathrm{~K}$ in order to get a deeper understanding of the crystallization mechanisms. The $\mathrm{T}_{\text {iso }}$ values were selected slightly above $\mathrm{T}_{\mathrm{g}, \mathrm{on}}$, but significantly lower than $\mathrm{T}_{1}$, see the arrows in Fig. 1. The length of the isothermal annealings was selected on preliminary considerations [38]. As seen in Fig. 6, each isotherm exhibits a single exothermic peak, which practically incorporates the $T_{1}$ crystallization process obtained during the linear heating, as will be confirmed later. From the analysis of the shape of the isothermal DSC-peak it can be concluded that crystallization takes place through a nucleation from the amorphous matrix and a subsequent growth mechanism [39]. With increasing annealing temperature, the peak maximum $\left(\mathrm{t}_{\mathrm{iso}}\right)$ occurs at shorter times (Table II). From the shift of $\mathrm{t}_{\text {iso }}$ as a function of $\mathrm{T}_{\mathrm{iso}}$, an apparent activation energy $\left(\mathrm{E}_{\mathrm{iso}}=110 \mathrm{kJmol}^{-1}\right)$ was obtained. The enthalpy release during the various isothermal annelaings $\left(\Delta \mathrm{H}_{\text {iso }}\right)$ slightly increases with $\mathrm{T}_{\text {iso }}$ (see Table II). The obtained value for $\Delta \mathrm{H}_{\text {iso }}$ is approximately equal to $\Delta \mathrm{H}_{1}$, indicating that the during the isothermal heat release the first linear heating DSC-peak is eliminated.

The crystallization kinetics of the as-cast $\mathrm{Mg}_{54} \mathrm{Cu}_{28} \mathrm{Ag}_{7} \mathrm{Y}_{11}$ can be studied through the isothermal DSC experiments by applying the Johnson-Mehl-Avrami (JMA) model [40], as follows. The crystalline transformed fraction during the first thermal event $(x(t))$ at an instant $\mathrm{T}_{\text {iso }}$ temperature can be obtained directly from the isothermal curves according to the following equation 


$$
x(t)=\frac{\int_{0}^{t} \dot{H}\left(t^{\prime}\right) \mathrm{dt}^{\prime}}{\Delta \mathrm{H}^{\text {iso }}},
$$

where $\dot{H}(t)$ is the measured heat flow at time $t$. Figure 7 a presents the $x(t)$ isothermal transformation curves at $\mathrm{T}_{\text {iso }}=450 \mathrm{~K}, \mathrm{~T}_{\text {iso }}=455 \mathrm{~K}$ and $\mathrm{T}_{\text {iso }}=460 \mathrm{~K}$ on a logarithmic scale calculated from $\mathrm{Eq}$ 4. As it is evident, the reaction is completed in shorter times with increasing the annealing temperature. According to the JMA analysis, the $\mathrm{x}(\mathrm{t})$ transformed fraction can be written as

$$
\mathrm{x}(\mathrm{t})=1-\exp \left[-\mathrm{K}\left(\mathrm{t}-\mathrm{t}_{0}\right)^{\mathrm{n}}\right]
$$

where $t_{0}$ is an incubation time, $\mathrm{n}$ is the Avrami exponent describing the mechanism of the transformation and the kinetic factor $\mathrm{K}(\mathrm{T})$ follows an Arrhenius behavior

$$
\mathrm{K}(\mathrm{T})=\mathrm{K}_{0} \exp \left(-\mathrm{E}_{\mathrm{a}} / \mathrm{RT}\right)
$$

where $K_{0}$ is a constant and $E_{a}$ is the apparent activation energy of crystallization. The values of $\mathrm{K}$ and $\mathrm{n}$ can be determined from the

$$
\ln \left[-\ln \left(1-\mathrm{x}\left(\mathrm{t}-\mathrm{t}_{0}\right)\right)\right]=\mathrm{n} \ln \mathrm{K}+\mathrm{n} \ln \left(\mathrm{t}-\mathrm{t}_{0}\right)
$$

equation. For single-step nucleation process, the $\ln \left[-\ln \left(1-\mathrm{x}\left(\mathrm{t}-\mathrm{t}_{0}\right)\right)\right]$ vs. $\ln \left(\mathrm{t}-\mathrm{t}_{0}\right)$ JMA plot is a straight line, and its slope and interception give $\mathrm{n}$ and $\mathrm{K}$, respectively. Plots of this kind for the different $T_{\text {iso }}$ temperatures are shown in Fig. $7 b$. As seen, a single exponent $(n=3.8)$ is 
necessary for $\mathrm{T}_{\mathrm{iso}}=450 \mathrm{~K}$ to fit the JMA function, corresponding to a uniform nucleation mechanism. On the other hand, the JMA plots of $\mathrm{T}_{\text {iso }}=455 \mathrm{~K}$ and $\mathrm{T}_{\text {iso }}=460 \mathrm{~K}$ cannot be fitted with a straight line, even with varying $\mathrm{t}_{0}$. In these cases more than one Avrami exponent is needed, because of the varying nucleation mechanism. The Avrami exponent can be written as

$$
\mathrm{n}=\mathrm{a}+\mathrm{d}^{*} \mathrm{p}
$$

where $\mathrm{a}$ is related to the nucleation rate, $\mathrm{d}$ represents the dimensionality of crystal growth and $\mathrm{p}$ refers to the mechanism that controls the growth [41]. The value 3.8 predicts interfacecontrolled 3-dimensional growth with decreasing nucleation rate.

An alternative experiment to get information on the crystallization mechanism under isothermal conditions is a linear heating scan following partial isothermal treatment for an instant time $t_{\mathrm{ann}}$. Assuming that the total enthalpy release during the isothermal pre-anneal and the subsequent linear heating run is constant, the transformed volume fraction of the first crystallization event $\left(\mathrm{x}\left(\mathrm{t}_{\mathrm{ann}}\right)\right)$ during the pre-anneal can be evaluated by obtaining the residual area of the first $\Delta \mathrm{H}_{1}\left(\mathrm{t}_{\mathrm{ann}}\right)$ crystallization reaction in the linear heating DSC experiments. Then the transformed volume fraction can be calculated as:

$$
\mathrm{x}\left(\mathrm{t}_{\mathrm{ann}}\right)=\frac{\Delta \mathrm{H}_{1}-\Delta \mathrm{H}_{1}\left(\mathrm{t}_{\mathrm{ann}}\right)}{\Delta \mathrm{H}_{1}} .
$$

Because of the single nucleation mechanism, $\mathrm{T}_{\text {iso }}=450 \mathrm{~K}$ temperature was chosen for this analysis, while the length of the pre-annealing treatment was selected as $t_{\mathrm{ann}}=2500 \mathrm{~s}, \mathrm{t}_{\mathrm{ann}}=$ $4000 \mathrm{~s}, \mathrm{t}_{\mathrm{ann}}=5000 \mathrm{~s}$ and $\mathrm{t}_{\mathrm{ann}}=7200 \mathrm{~s}$, as indicated by arrows in Fig. 6. Figure 8 presents the 
thermograms obtained during continuous heating corresponding to the different $t_{a n n}$ states. As evidenced, the area of the endothermic contribution $\Delta \mathrm{H}_{\mathrm{g}}$ diminishes progressively with increasing annealing time. At the same time the enthalpy release $\Delta \mathrm{H}_{1}\left(\mathrm{t}_{\mathrm{ann}}\right)$ also decreases monotonously, while $\Delta \mathrm{H}_{2}\left(\mathrm{t}_{\mathrm{ann}}\right)$ remains practically constant (see Table III). It is also noted that the second crystallization step splits into two sub-peaks $\left(\Delta \mathrm{H}_{2}\right.$ and $\left.\Delta \mathrm{H}_{2^{*}}\right)$ at longer annealing times, corresponding to a potentially different chemical composition of the residual amorphous matrix. The calculated values of $x\left(t_{a n n}\right)$ plotted in Fig. 7 a fit satisfactorily to the transformation curve obtained from isothermal measurement, indicating that both procedures are valid for determining the transformed crystalline fraction. The variation of $\mathrm{T}_{\mathrm{g}, \mathrm{on}}, \mathrm{T}_{1}$ and $\mathrm{T}_{2}$ as a function of $t_{a n n}$ can be seen in Fig 9. Each characteristic temperature obeys a gradual decrease, which reflects to decreasing thermal stability and a compositional change of the residual amorphous matrix.

The evolution of the crystalline phases during isothermal pre-anneals was also monitored by $\mathrm{X}$-ray diffraction. The diffractograms obtained after annealing at $\mathrm{T}_{\mathrm{iso}}=450 \mathrm{~K}$ for various $\mathrm{t}_{\mathrm{ann}}$ times reveals the gradual reduction of the amorphous component (see Fig. 10). The first crystalline Bragg-peaks superimposed on the halo appear already after $2500 \mathrm{~s}$ of devitrification, a simultaneous precipitation of $\mathrm{Mg}_{2} \mathrm{Cu}, \mathrm{Cu}_{2} \mathrm{Y}$ and $\mathrm{MgY}$ occurs. As the isothermal annealing prolongs, the crystalline peaks become more intense and sharper indicating a moderate grain growth (from 15 to $18 \mathrm{~nm}$ ), in accordance with the calculated value of the JMA parameter. The presence of $\mathrm{AgMg}_{3}$ is evident only after longer annealings. The X-ray diffractogram obtained after $\mathrm{t}_{\mathrm{ann}}=7200 \mathrm{~s}$ exhibits similar phases to those found after linear heating at $20 \mathrm{Kmin}^{-1}$ up to $620 \mathrm{~K}$.

In order to reveal the details of the microstructure and morphology of the partially crystallized $\mathrm{Mg}_{54} \mathrm{Cu}_{28} \mathrm{Ag}_{7} \mathrm{Y}_{11}$ alloy, additional transmission electron microscopy were conducted on the sampler annealed at $T_{i s o}=450 \mathrm{~K}$ for $t_{a n n}=2500 \mathrm{~s}$ and $t_{a n n}=7200 \mathrm{~s}$. At first glance, $a$ 
remarkable difference cannot be resolved between the two bright field images, in both cases several nanocrystals exhibiting periodic atomic structure are homogenously dispersed in the aperiodic amorphous background (Fig. 11).

\subsection{Hydrogen-sorption}

Figure 12 presents the HP-DSC measurements of the reference $\mathrm{Mg}_{54} \mathrm{Cu}_{28} \mathrm{Ag}_{7} \mathrm{Y}_{11}$ fully amorphous BMG, partially crystallized states obtained either by continuous or isothermal annealing treatment and the fully crystallized alloy. The clear endothermic peak in the thermogram of the amorphous alloy $\left(435 \mathrm{~K}-465 \mathrm{~K}\right.$ with a maximum at $\left.\mathrm{T}_{\mathrm{des}}=451 \mathrm{~K}\right)$ can be assigned to the release of hydrogen. (It is noted that hydrogen absorption measurements were also carried out on all states, however, the effect is less characteristic, most probably due to baseline instabilities). As one can notice, this temperature range fairly well coincides with the SCL range of the alloy, namely the system remains in the glassy structure during the whole process of dehydrogenation. Complimentary XRD measurements has also been carried out on the fully amorphous alloy before linear heating, right after the hydrogen pressure was set to the constant pressure of 60 bar in the HP-DSC. Accordingly, it is stated that no crystalline hydride phase(s) formation is observed. A second diffractogram was also performed after the dehydrogenation in the HP-DSC device (after linear heating up to $470 \mathrm{~K}$ ), confirming the presence only of the amorphous phase. The area of the endothermic peak corresponds to an enthalpy change of $\Delta \mathrm{H}_{\mathrm{des}}=-3.6 \mathrm{Jg}^{-1}$, which value proves the release of a hydrogen under the conditions of the HP-DSC. A repeating heating scan after a second hydrogenation exhibits the similar dehydrogenation behaviour, indicating that the $\mathrm{H}$-uptake and release is an inherent reversible process of this glass, which do not frustrate of the as-cast atomic structure. A lessintense $\mathrm{H}$-desorption peak $\left(\Delta \mathrm{H}_{\mathrm{des}}=-2.3 \mathrm{Jg}^{-1}\right)$ at the same temperature characterizes the thermogram of the alloy treated isothermally at $T_{\text {iso }}=450 \mathrm{~K}$ for $\mathrm{t}_{\mathrm{ann}}=2500 \mathrm{~s}$. A significant 
drop in the temperature of desorption $\left(\mathrm{T}_{\mathrm{des}} \sim 427 \mathrm{~K}\right)$ occurs after prolonged isothermal annealing $\left(\mathrm{t}_{\mathrm{ann}}=7200 \mathrm{~s}\right)$, which is associated with a remarkable decrease in the storage capacity $\left(\Delta \mathrm{H}_{\mathrm{des}}=-0.8 \mathrm{Jg}^{-1}\right)$. Very similar features characterize the thermogram of the partially crystallized sample $\left(\mathrm{T}_{\mathrm{des}} \sim 425 \mathrm{~K}, \Delta \mathrm{H}_{\mathrm{des}}=-0.3 \mathrm{Jg}^{-1}\right)$ treated by continuous heating above the first crystallization peak (lin $518 \mathrm{~K}$ ). As also noticed, the fully crystallized sample (lin $620 \mathrm{~K}$ ) possesses no detectable hydrogen sorption. As a comparison of the calorimetric and H-storage experiments, we can conclude that the decreasing amorphous content results in smaller hydrogen storage capacity and lower temperature of desorption.

\section{Discussion}

According to the "three dimensional pinpointing approach" of Ma et al. [26], it was found that the $\mathrm{Mg}-\mathrm{Cu}-\mathrm{Ag}-\mathrm{Y}$ system exhibits extraordinary GFA in a rather wide composition region, with the best BMG-forming concentration located at $\mathrm{Mg}_{54} \mathrm{Cu}_{28} \mathrm{Ag}_{7} \mathrm{Y}_{11}$. Indeed, our comprehensive thermal characterization confirmed that this BMG shows excellent GFA parameters including $\mathrm{T}_{\mathrm{g}, \mathrm{on}}=432 \mathrm{~K}, \Delta \mathrm{T}_{\mathrm{x}}=49 \mathrm{~K}, \mathrm{~T}_{\mathrm{rg}}=0.592$ and $\gamma=0.414$.

It is well known that BMG formation is favored when the nucleation and growth of crystalline phases cannot compete with the glass formation. The enhancement of the GFA and the thermal stability of the SCL appear to correlate with the large atomic mismatch, electronic effects and negative heat of mixing between the constituents [19]. In our particular system the following atomic sizes are present: $d_{M g}=0.16 \mathrm{~nm}, d_{C u}=0.128 \mathrm{~nm}, d_{\mathrm{Ag}}=0.144 \mathrm{~nm}$ and $d_{\mathrm{Y}}=$ $0.180 \mathrm{~nm}$. As was shown, Ag addition to several good glass formers, such as $\mathrm{Mg}-\mathrm{Cu}-\mathrm{Y}$ [24], Mg-Cu-Gd-Y [23], Cu-Zr [36] broadens the supercooled liquid region, decrease the fragility and increases the resistance against crystallization. Silver optimizes the atomic packing because of volume mismatch and negative heat of mixing with the other constituents is larger than that of $\mathrm{Cu}$, such as $\mathrm{E}_{\mathrm{Ag}-\mathrm{Mg}}=-10 \mathrm{~kJ} / \mathrm{mol}, \mathrm{E}_{\mathrm{Cu}-\mathrm{Mg}}=-3 \mathrm{~kJ} / \mathrm{mol} \mathrm{E}_{\mathrm{Ag}-\mathrm{Y}}=-29 \mathrm{~kJ} / \mathrm{mol} \mathrm{E}_{\mathrm{Cu}-\mathrm{Y}}=-$ 
$22 \mathrm{~kJ} / \mathrm{mol}$ [24]. Consequently, the crystalline state is destabilized, in line with the low value of m. At the same time the activation energy decreases with Ag-addition [22], see also Fig. 2. Stronger metallic glass formers with smaller fragility $(<40)$ are susceptible to strong chemical short range order (SRO), less free volume and increased amount of directional bonds [42]. Indeed, molecular dynamic simulations accompanied with X-ray absorption fine structure technique have demonstrated to formation of several local structural units in a $\mathrm{MgCu}(\mathrm{Ag}) \mathrm{Gd}$ alloy [43]. Moreover, the similar coordination numbers around each constituent both in the SCL region and in the equilibrium liquid state (above $\mathrm{T}_{\mathrm{m}}$ ) explain that this strong glass can be regarded as a "frozen" liquid [43].

In the following, let us discuss the correlation between observed H-storage properties and microstructure of the $\mathrm{Mg}_{54} \mathrm{Cu}_{28} \mathrm{Ag}_{7} \mathrm{Y}_{11}$ BMG. Based on Fig. 12, it is obtained that the fully amorphous glassy structure presents the highest storage capacity at a relatively low absorption temperature, compared to nanocrystalline Mg-based powders [4,5]. Although, H-storage capacity reduces both during continuous heating and isothermal annealing, the absorption temperature shifted towards lower temperatures in the case of partially crystalline samples, and this may be advantageous in terms of practical applications. At the same time, supplementary XRD and TEM analysis demonstrated that the microstructure (crystalline phases, average crystallite size) hardly varies with $\mathrm{t}_{\mathrm{ann}}$ during isothermal annealing, or with the final temperature during continuous heating experiments (see Figs. 4, 10 and 11). The only exceptional difference between these states is the amount of the crystalline fraction, which is undoubtedly confirmed by the very similar H-absorption behavior and similar transformed volume fraction of the $t_{a n n}=7200 \mathrm{~s}$ and lin $518 \mathrm{~K}$ states. (In both cases the $\mathrm{T}_{1}$ devitrification stage is completed). Since several crystalline phases $\left(\mathrm{Mg}_{2} \mathrm{Cu}, \mathrm{Cu}_{2} \mathrm{Y}, \mathrm{MgY}\right.$ and $\left.\mathrm{AgMg}_{3}\right)$ nucleate simultaneously from the amorphous background, the average atomic displacement during this process is relatively short and comparable to the crystallite size $(\sim 10$ 
$\mathrm{nm})$. At the same time average concentration of the residual matrix slightly changes, however, calorimetric experiments exhibit significant differences due to even minor changes of BMG concentration, as Fig. 8 also reveals. Consequently, the effect of chemical heterogeneities on length-scale larger than a couple of $10 \mathrm{~nm}$ is negligible at any heat-treated state. Note that during primary crystallization, the atomic diffusion length during crystallization can be remarkably higher accompanied with a drastic change in the matrix concentration. Based on the above experimental results, it is concluded that the hydrogen storage capacity practically correlates only with the crystalline volume fraction of the partially crystallized $\mathrm{Mg}_{54} \mathrm{Cu}_{28} \mathrm{Ag}_{7} \mathrm{Y}_{11} \mathrm{BMG}$ and additional parameters, such as crystalline phase selection, crystallite size and change in the average matrix concentration do not play a significant role. However, molecular dynamic simulations revealed a significant difference in the SRO of the major crystalline phase $\left(\mathrm{Mg}_{2} \mathrm{Cu}\right)$ and the glassy structure in $\mathrm{MgCu}(\mathrm{Ag}) \mathrm{Gd}$ BMG [43]. In the crystalline phase the $\mathrm{Mg}$-centered polyhedron is $\langle 0,0,12,3\rangle$ while the $\mathrm{Cu}$-centered cluster is $\langle 0,2,8,0\rangle$ [43], where the integers in $<. .>$ denote the number of triangles, rectangles, pentathlons and hexagons, respectively, on the cluster surface. Notwithstanding, the SRO around the $\mathrm{Mg}$ atoms is significantly different $(<0,2,8,2\rangle$ and $\langle 0,3,6,4\rangle)$ in the glassy state, which, on one hand suppresses the precipitation of the $\mathrm{Mg}_{2} \mathrm{Cu}$ during cooling the liquid below the glass transition and, on the other hand, can lead to an easier capture of hydrogen atoms. As it was evidenced from complimentary XRD analysis and HP-DSC scan, the fully crystallized alloy does not absorb hydrogen at all (see Fig. 12) even though MgY is among the nucleated phases, consequently it is reasonable to assume that the local atomic (glassy) structure in the supercooled liquid is accountant for the observed hydrogen sorption.

The connection between the glassy nature and the storage properties of the $\mathrm{Mg}_{54} \mathrm{Cu}_{28} \mathrm{Ag}_{7} \mathrm{Y}_{11}$ BMG is further supported by the mutual decrease in the glass transition temperature $\left(\mathrm{T}_{\mathrm{g}, \mathrm{on}}\right)$ and the H-sorption temperature $\left(\mathrm{T}_{\mathrm{des}}\right)$ with increasing crystalline volume fraction (see Table 
III and Figs. 8 and 12). Accordingly, the intrinsic structure of the amorphous phase plays a much more crucial role in the dehydrogenation than the presence or lack of any $\mathrm{H}$-absorbing phase.

\section{Conclusions}

Comprehensive thermal characterization of as-cast $\mathrm{Mg}_{54} \mathrm{Cu}_{28} \mathrm{Ag}_{7} \mathrm{Y}_{11}$ bulk metallic glass revealed that this particular composition exhibits excellent glass forming ability, including $\mathrm{T}_{\mathrm{g}, \mathrm{on}}=49 \mathrm{~K}, \Delta \mathrm{T}_{\mathrm{x}}=49 \mathrm{~K}, \mathrm{~T}_{\mathrm{rg}}=0.592$ and $\gamma=0.414$. It was found that the calorimetric glass transition follows a Vogel-Fulcher-Tammann-like behavior. The calculated fragility parameter $(\mathrm{m}=38)$ corresponds to the intermediate category of glass forming liquids, close to the strong limit.

Both continuous heating and isothermal annealing experiments provoke the joint formation of several crystalline phases $\left(\mathrm{Mg}_{2} \mathrm{Cu}, \mathrm{Cu}_{2} \mathrm{Y}, \mathrm{MgY}, \mathrm{AgMg}_{3}\right)$, which requires short atomic movements. Interestingly, the average size of these nanocrystals is practically unchanged during thermal treatment, only their volume fraction increases. According to the JohnsonMehl-Avrami analysis the growth of the nanocrystals predicts 3-dimensional interfacecontrolled growth with decreasing nucleation rate.

Hydrogen-sorption experiments indicate that the as-cast fully amorphous alloy exhibits the largest enthalpy of desorption, compared to the partially and fully crystallized states. Since the fully crystallized alloy does not desorb hydrogen, it is assumed that the local atomic structure of the glass is accountant for the hydrogen release. The temperature of desorption fairly well coincides with the supercooled liquid range of the glass.

\section{Acknowledgement}




\begin{abstract}
Á. R. is indebted for the János Bolyai Research Scholarship of the Hungarian Academy of Sciences. T.S. is grateful to the project UNION and FP7 project Beyond Everest. We acknowledge the support of the COST Action MP1103. The authors appreciate the support of G. Varga in the SEM experiments. Preparation of the TEM lamellae by N. Szász is acknowledged.
\end{abstract}




\section{References}

[1] Schlapbach L, Züttel A. Hydrogen-storage materials for mobile applications. Nature 2001;414:353-8.

[2] Varin RA, Czujko T, Wronski ZS. Nanomaterials for Solid State Hydrogen Storage. New York, NY, USA: Springer Science; 2009.

[3] Varin RA, Czujko T, Chiu Ch, Wronski Z. Particle size effects on the desorption properties of nanostructured magnesium dihydride $\left(\mathrm{MgH}_{2}\right)$ synthesized by controlled reactive mechanical milling (CRMM). J Alloys Compd 2006;424:356-64.

[4] Zaluski L, Zaluska A, Tessier P, Ström-Olsen JO, Schulz R. Nanocrystalline Hydrogen Absorbing Alloys. Mater Science Forum 1996;225:853-8.

[5] Fátay D, Révész Á, Spassov T. Particle size and catalytic effect on the dehydriding of $\mathrm{MgH}_{2}$. J Alloys Compds 2005;399:237-241.

[6] Vittori Antisari M, Aurora A, Mirabile Gattia D, Montone A. On the nucleation step in the $\mathrm{Mg}-\mathrm{MgH}_{2}$ phase transformation. Scripta Mater 2009;61:1064-7.

[7] Oelerich W, Klassen T, Bormann R. Metal oxides as catalysts for improved hydrogen sorption in nanocrystalline Mg-based materials. J Alloys Compd 2001;315:237-42.

[8] Révész Á, Gajdics M, Spassov T. Microstructural evolution of ball-milled Mg-Ni powder during hydrogen sorption. Int J Hydrogen Energy 2013;38:8342-49.

[9] Zhang YH, Li BW, Ren HP, Guo SH, Wang XL. Hydrogenation and dehydrogenation behaviours of nanocrystalline $\mathrm{Mg}_{20} \mathrm{Ni}_{10-\mathrm{x}} \mathrm{Cu}_{\mathrm{x}}(\mathrm{x}=0-4)$ alloys prepared by melt spinning. Int $\mathrm{J}$ Hydrogen Energy 2010;35:2040-7.

[10] Zhang YH, Zhao DL, Li BW, Ren HP, Guo SH, Wang XL. Electrochemical hydrogen storage characteristics of nanocrystalline $\mathrm{Mg}_{20} \mathrm{Ni}_{10-\mathrm{x}} \mathrm{Cu}_{\mathrm{x}}(\mathrm{x}=0-4)$ alloys prepared by meltspinning. J Alloys Compds 2010;491(1-2):589-94. 
[11] Zhang YH, Li BW, Ren HP, Hu F, Zhang GF, Guo SH. Gaseous and electrochemical hydrogen storage kinetics of nanocrystalline $\mathrm{Mg} 2 \mathrm{Ni}$-type alloy prepared by rapid quenching. $\mathrm{J}$ Alloys Compds 2011;509:5604-10.

[12] Bendersky LA, Chiu C, Skripnyuk VM, Rabkin E. Effect of rapid solidification on hydrogen solubility in Mg-rich Mg-Ni alloys. Int J Hydrogen Energy 2011;36:5388-99.

[13] Kalinichenka S, Röntzsch L, Baehetz C, Kieback B, Hydrogen desorption kinetics of melt-spun and hydrogenated $\mathrm{Mg}_{90} \mathrm{Ni}_{10}$ and $\mathrm{Mg}_{80} \mathrm{Ni}_{10} \mathrm{Y}_{10}$ using in situ synchrotron, X-ray diffraction and thermogravimetry. J Alloys Compds 2010;496:608-13.

[14] Denys RV, Poletaev AA, Maehlen JP, Solberg JK, Tarasov BP, Yartys VA. Nanostructured rapidly solidified $\mathrm{LaMg}_{11} \mathrm{Ni}$ alloy. II. In situ synchrotron X-ray diffraction studies of hydrogen absorption-desorption behaviours. Int J Hydrogen Energy 2012;37:571022.

[15] Spassov T, Köster U, Thermal stability and hydriding properties of nanocrystalline meltspun $\mathrm{Mg}_{63} \mathrm{Ni}_{30} \mathrm{Y}_{7}$ alloy. J Alloys Compds 1998;279:279-86.

[16] Révész Á, Kis-Tóth Á, Varga LK, Schafler E, Bakonyi I, Spassov T. Hydrogen storage of melt-spun amorphous $\mathrm{Mg}_{65} \mathrm{Ni}_{20} \mathrm{Cu}_{5} \mathrm{Y}_{10}$ alloy deformed by high-pressure torsion. Int $\mathrm{J}$ Hydrogen Energy 2012;37:5769-76.

[17] Teresiak A, Uhlemann M, Gebert A, Thomas J, Eckert J, Schultz L. Formation of nanostructured $\mathrm{LaMg}_{2} \mathrm{Ni}$ by rapid quenching and intensive milling and its hydrogen reactivity. J Alloys Compds 2009;481:144-51.

[18] Zhang QA, Jiang CJ, Liu DD. Comparative investigations on the hydrogenation characteristics and hydrogen storage kinetics of melt-spun $\mathrm{Mg}_{10} \mathrm{NiR}(\mathrm{R}=\mathrm{La}, \mathrm{Nd}$ and $\mathrm{Sm}$ ) alloys. Int J Hydrogen Energy 2012;37:10709-14.

[19] Inoue A. Stabilization of metallic supercooled liquid and bulk amorphous alloys. Acta Materialia 2000;48:279-306.

[20] Miller M, Liaw P: Editors. Bulk Metallic Glasses, An Overview. New York, NY, USA: Springer Science; 2009. 
[21] Inoue A, Nakamura T, Nishiyama N, Masumoto T. Mg-Cu-Y bulk amorphous alloys with high tensile strength produced by a high-pressure die casting method. Materials Transactions JIM 1992;33:937-45.

[22] Hui X, Sun CY, Zhang CM, Liu SN, Wang ER, Wang ML, Chen GL. Mg-Cu-Y-Ag bulk metallic glasses with enhanced compressive strength and plasticity. J Alloys Compds 2010;504S:S6-9.

[23] Soubeyroux JL, Puech S, Blandin JJ. Effect of silver on the glass forming ability of MgCuGdY bulk metallic glasses. J Alloys Compds 2009;483:107-11.

[24] Park ES, Kang HG, Kim WT, Kim DH. The effect of Ag addition on the glass-forming ability of $\mathrm{Mg}-\mathrm{Cu}-\mathrm{Y}$ metallic glass alloys. J Non-Crystalline Solids 2001;279:154-60.

[25] Madge SV, Greer AL. Effect of Ag addition on the glass-forming ability and thermal stability of Mg-Cu-Y alloys. Mater Science Engineering A 2004;375-377:759-62.

[26] Ma H, Shi LL, Xu J, Li Y, Ma E. Discovering inch-diameter metallic glasses in threedimensional composition space. Applied Phys Lett 2005;87:181915.

[27] Klug HP, Alexander LE, X-ray diffraction procedures for polycrystalline and amorphous materials. New York, NY, USA: Wiley; 1974.

[28] Kissinger HE. Reaction kinetics in differential thermal analysis. Analytical Chemistry 1957;29:1702-06.

[29] Soubeyroux JL, Puech S. Phases formation during heating of $\mathrm{Mg}-\mathrm{Cu}-\mathrm{Ag}-\mathrm{Y}$ bulk metallic glasses J Alloys Compds 2010;495:330-3.

[30] Mitrovic N, Roth S, Eckert J. Kinetics of the glass-transition and crystallization process of $\mathrm{Fe}_{72-\mathrm{x}} \mathrm{Nb}_{\mathrm{x}} \mathrm{Al}_{5} \mathrm{Ga}_{2} \mathrm{P}_{11} \mathrm{C}_{6} \mathrm{~B}_{4}(\mathrm{x}=0,2)$ metallic glasses. Applied Phys Lett 2001;78:2145-47.

[31] Révész Á. Crystallization kinetics and thermal stability of an amorphous $\mathrm{Fe}_{77} \mathrm{C}_{5} \mathrm{~B}_{4} \mathrm{Al}_{2} \mathrm{GaP}_{9} \mathrm{Si}_{2}$ bulk metallic glass. J Thermal Anal Calorimetry 2008;91:879-84.

[32] Zheng Q, Xu J, Ma E. High glass-forming ability correlated with fragility of $\mathrm{Mg}-\mathrm{Cu}$ (Ag)-Gd alloys. J Applied Phys 2007;102:113519. 
[33] Brüning R, Samwer K. Glass transition on long time scales. Phys Rev B 1992;46:1131822.

[34] Perera DN. Compilation of the fragility parameters for several glass-forming metallic alloys. J Phys: Condensed Mater 1999;11:3807-12.

[35] Angell CA. Formation of Glasses from Liquids and Biopolymers. Science 1995;267:1924-35.

[36] Song KK, Gargarella P, Pauly S, Ma GZ, Kühn U, Eckert J. Correlation between glassforming ability, thermal stability, and crystallization kinetics of $\mathrm{Cu}-\mathrm{Zr}-\mathrm{Ag}$ metallic glasses $\mathrm{J}$ Applied Phys 2012;112:063503.

[37] Battezzati L, Castellero A, Rizzi P. On the glass transition in metallic melts. J NonCrystalline Solids 2007;353:3318-26.

[38] Révész Á, Lendvai J, Cziráki Á, Liebermann HH, Bakonyi I. Formation of nanocrystalline phases during thermal decomposition of amorphous Ni-P alloys by isothermal annealing. J Nanosci Nanotech 2001;1:191-200.

[39] Chen LC, Spaepen F. Calorimetric evidence for the micro-quasicrystalline structure of 'amorphous' Al/transition metal alloys. Nature 1988;336:366-8.

[40] Avrami M. Kinetics of phase change III. Granulation, phase change, and microstructure. J Chem. Phys 1941;9:177-184.

[41] Christian JW. The theory of transformations in metals and alloys, $2^{\text {nd }}$ edition, Oxford, UK: Pergamon; 1975.

[42] Busch R, Bakke E, Johnson WL. Viscosity of the supercooled liquid and relaxation at the glass transition of the $\mathrm{Zr}_{46.75} \mathrm{Ti}_{8.25} \mathrm{Cu}_{7.5} \mathrm{Ni}_{10} \mathrm{Be}_{27.5}$ bulk metallic glass forming alloy. Acta Mater 1998;46:4725-32.

[43] Wang XD, Lou HB, Wang SG, Xu J, Jiang JZ. Atomic packing in $\mathrm{Mg}_{61} \mathrm{Cu}_{28} \mathrm{Gd}_{11}$ bulk metallic glass. Applied Phys Lett 2011;98:031901. 


\section{Figure captions}

Figure 1. Continuous-heating DSC curve of the as-cast $\mathrm{Mg}_{54} \mathrm{Cu}_{28} \mathrm{Ag}_{7} \mathrm{Y}_{11}$ bulk metallic glass obtained at $20 \mathrm{Kmin}^{-1}$. The arrows indicate the temperature of annealing. Left inset is an enlarged part of the DSC trace showing how to determine the characteristic temperatures. Right inset presents the melting endotherm with the melting and liquidus temperatures.

Figure 2. Series of Continuous-heating DSC measurements of the as-cast $M_{54} \mathrm{Cu}_{28} \mathrm{Ag}_{7} \mathrm{Y}_{11}$ BMG obtained at different heating rates. The inset shows the Kissinger plots corresponding to the glass transition and the two crystallization transformation.

Figure 3. Dependence of the onset of the glass transition on the logarithm of the heating rate. $\mathrm{T}_{\mathrm{g}, \text { on }}$ was fitted by Eq. 2 . Inset shows the width of the glass transition on the logarithm of the heating rate.

Figure 4. $\mathrm{X}$-ray diffraction patterns corresponding to the as-cast $\mathrm{Mg}_{54} \mathrm{Cu}_{28} \mathrm{Ag}_{7} \mathrm{Y}_{11} \mathrm{BMG}$ and the states obtained by continuous heating.

Figure 5. Typical SEM-FIB images taken from the inner surface of the ion-milled notch corresponding to the amorphous $\mathrm{Mg}_{54} \mathrm{Cu}_{28} \mathrm{Ag}_{7} \mathrm{Y}_{11}$ alloy.

Figure 6. Isothermal DSC thermograms of the $\mathrm{Mg}_{54} \mathrm{Cu}_{28} \mathrm{Ag}_{7} \mathrm{Y}_{11}$ BMG. Arrows denote the length of pre-anneals.

Figure 7. (a) $x(t)$ isothermal transformation curves corresponding to different annealing temperatures calculated from Eq 4 and (b) the corresponding JMA plots.

Figure 8. Continuous heating DSC curves obtained after partial annealing of the as-cast glass

Figure 9. Variation of the peak temperatures with the duration of pre-anneals. 
Figure 10. X-ray diffraction patterns performed after pre-anneals of the ${ } g_{54} \mathrm{Cu}_{28} \mathrm{Ag}_{7} \mathrm{Y}_{11}$ BMG.

Figure 11. TEM images corresponding to pre-anneals of the as-cast glass at $\mathrm{T}_{\text {iso }}=450 \mathrm{~K}$ for (a) $t_{a n n}=2500 \mathrm{~s}$ and (b) $t_{a n n}=7200 \mathrm{~s}$. White contour lines indicate the precipitated nanocrystals

Figure 12. High-pressure DSC measurements on the as-cast, partially crystalline and fully crystalline $\mathrm{Mg}_{54} \mathrm{Cu}_{28} \mathrm{Ag}_{7} \mathrm{Y}_{11}$ alloy

\section{Table captions}

Table I. Characteristic parameters [onset $\left(\mathrm{T}_{\mathrm{g}, \mathrm{on}}\right)$ and the end $\left(\mathrm{T}_{\mathrm{g}, \text { end }}\right)$ of the glass transition, onset of crystallization $\left(\mathrm{T}_{\mathrm{x}, \text { on }}\right)$, width of the supercooled liquid region $\left(\Delta \mathrm{T}_{\mathrm{x}}\right)$, crystallization peaks $\left(\mathrm{T}_{1}, \mathrm{~T}_{2}\right)$ and transformation enthalpies $\left(\left(\Delta \mathrm{H}_{\mathrm{g}}, \Delta \mathrm{H}_{1}\right.\right.$ and $\left.\left.\Delta \mathrm{H}_{2}\right)\right]$ obtained from continuous heating DSC experiments at different heating rate $(\beta)$ for the $\mathrm{Mg}_{54} \mathrm{Cu}_{28} \mathrm{Ag}_{7} \mathrm{Y}_{11}$ bulk metallic glass. Solidus $\left(\mathrm{T}_{\mathrm{m}}\right)$ and liquidus $\left(\mathrm{T}_{1}\right)$ temperatures obtained at heating rate of $\beta=20 \mathrm{Kmin}^{-1}$ are also tabulated.

Table II. Maximum of the calorimetric peak temperature $\left(\mathrm{t}_{\mathrm{iso}}\right)$ and enthalpy release $\left(\Delta \mathrm{H}_{\mathrm{iso}}\right)$ as a function of the isothermal annealing temperature $\left(\mathrm{T}_{\text {iso }}\right)$.

Table III. Variation of the characteristic thermodynamic parameters of continuous heating following partial isothermal treatment for different annealing times $\mathrm{t}_{\mathrm{ann}}$. 


\begin{tabular}{|c|c|c|c|c|c|c|c|c|c|c|c|}
\hline$\beta\left(\mathrm{Kmin}^{-1}\right)$ & $\begin{array}{l}\mathrm{T}_{\mathrm{g}, \text { on }} \\
(\mathrm{K})\end{array}$ & $\begin{array}{l}T_{g, e n d} \\
(\mathrm{~K})\end{array}$ & $\begin{array}{l}\mathrm{T}_{1, \text { on }} \\
(\mathrm{K})\end{array}$ & $\begin{array}{l}\Delta \mathrm{T}_{\mathrm{x}} \\
(\mathrm{K})\end{array}$ & $\begin{array}{l}\mathrm{T}_{1} \\
(\mathrm{~K})\end{array}$ & $\begin{array}{l}\mathrm{T}_{2} \\
(\mathrm{~K})\end{array}$ & $\begin{array}{l}T_{m} \\
(\mathrm{~K}) \\
\end{array}$ & $\mathrm{T}_{1}(\mathrm{~K})$ & $\begin{array}{l}\Delta \mathrm{H}_{\mathrm{g}}\left(\mathrm{Jg}^{-}\right. \\
\mathrm{J}^{-}\end{array}$ & $\begin{array}{l}\Delta \mathrm{H}_{1} \\
\left(\mathrm{Jg}^{-1}\right)\end{array}$ & $\begin{array}{l}\Delta \mathrm{H}_{2} \\
\left(\mathrm{Jg}^{-1}\right)\end{array}$ \\
\hline 2.5 & 424 & 442 & 464 & 40 & 476 & 523 & -- & -- & $-16,7$ & 45 & 7 \\
\hline 5 & 426 & 445 & 471 & 45 & 482 & 532 & -- & -- & $-15,7$ & 46 & 7 \\
\hline 10 & 428 & 449 & 475 & 47 & 488 & 541 & -- & -- & $-15,6$ & 47 & 11 \\
\hline 20 & 432 & 454 & 481 & 49 & 495 & 549 & 702 & 729 & $-14,7$ & 49 & 10 \\
\hline 40 & 436 & 460 & 489 & 53 & 501 & 556 & -- & -- & $-14,8$ & 51 & 11 \\
\hline 80 & 440 & 466 & 493 & 53 & 507 & 563 & -- & -- & $-16,0$ & 47 & 9 \\
\hline
\end{tabular}

Table I 
Table2

International Journal of Hydrogen Energy 39 (2014) 9230-9240

\begin{tabular}{|c|c|c|}
\hline $\mathrm{T}_{\text {iso }}(\mathrm{K})$ & $\mathrm{t}_{\text {iso }}(\mathrm{s})$ & $\Delta \mathrm{H}_{\mathrm{iso}}(\mathrm{J} / \mathrm{g})$ \\
\hline 450 & 5374 & 35 \\
\hline 455 & 2995 & 39 \\
\hline 460 & 1388 & 42 \\
\hline
\end{tabular}

Table II 
International Journal of Hydrogen Energy 39 (2014) 9230-9240

\begin{tabular}{|c|c|c|c|c|c|}
\hline & As-cast & $2000 \mathrm{~s}$ & $4000 \mathrm{~s}$ & $5000 \mathrm{~s}$ & $7200 \mathrm{~s}$ \\
\hline $\mathrm{T}_{\mathrm{g}, \text { on }}(\mathrm{K})$ & 432 & 430 & 427 & 425 & -- \\
\hline $\mathrm{T}_{1}(\mathrm{~K})$ & 495 & 487 & 484 & 478 & -- \\
\hline $\mathrm{T}_{2}(\mathrm{~K})$ & 549 & 546 & 543 & 538 & 530 \\
\hline $\mathrm{T}_{2^{*}}(\mathrm{~K})$ & -- & -- & -- & 565 & 550 \\
\hline$\Delta \mathrm{H}_{\mathrm{g}}(\mathrm{J} / \mathrm{g})$ & $-14,7$ & $-7,4$ & $-5,5$ & $-1,0$ & $-0,4$ \\
\hline$\Delta \mathrm{H}_{1}(\mathrm{~J} / \mathrm{g})$ & 49 & 45 & 35 & 15 & 0 \\
\hline$\Delta \mathrm{H}_{2}(\mathrm{~J} / \mathrm{g})$ & 10 & 10 & 11 & 11 & 11 \\
\hline$\Delta \mathrm{H}_{2 *}(\mathrm{~J} / \mathrm{g})$ & -- & -- & -- & 3 & 6 \\
\hline
\end{tabular}

Table III 


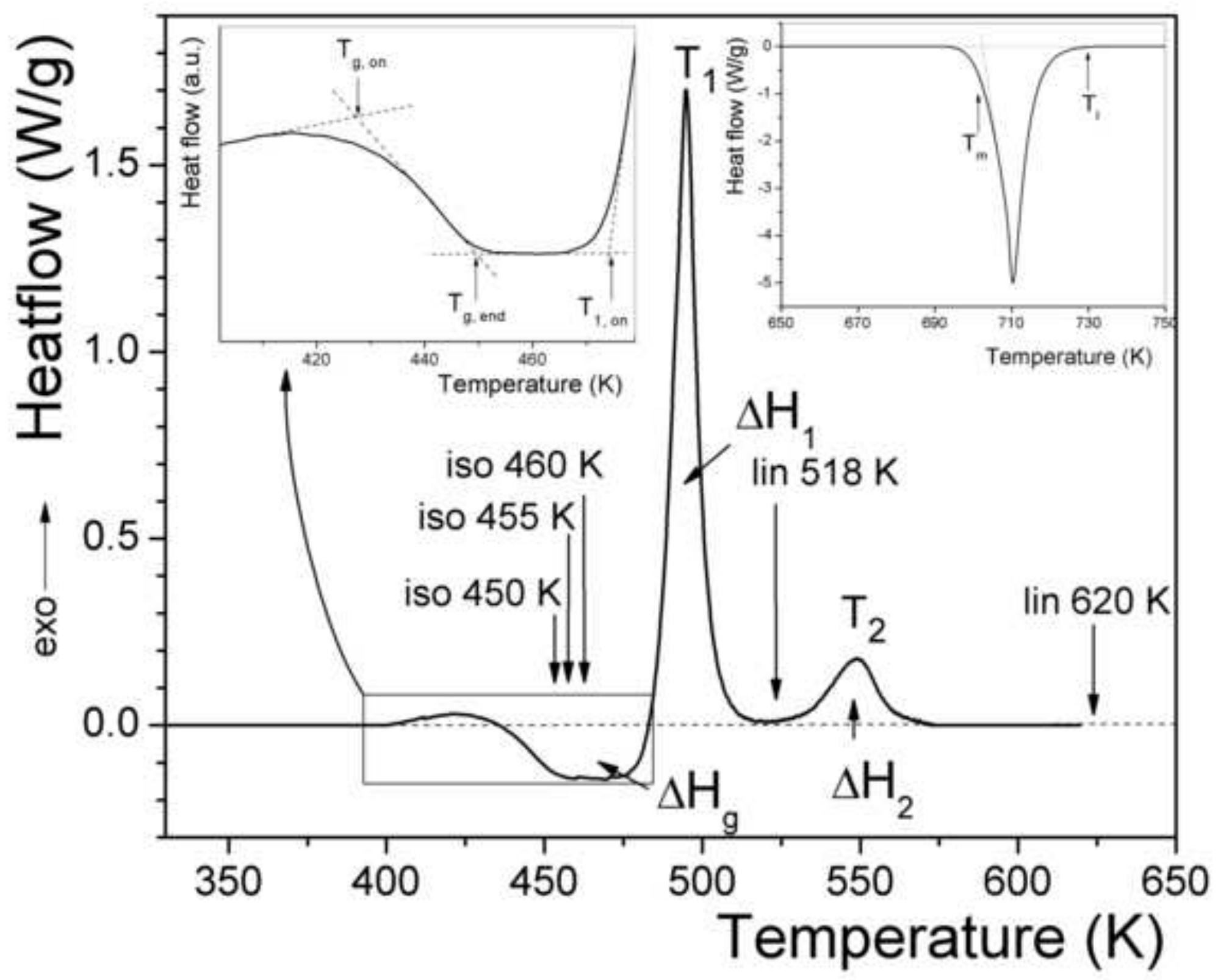




\section{Fure2}

Click here to download high resolution image

International Journal of Hydrogen Energy 39 (2014) 9230-9240

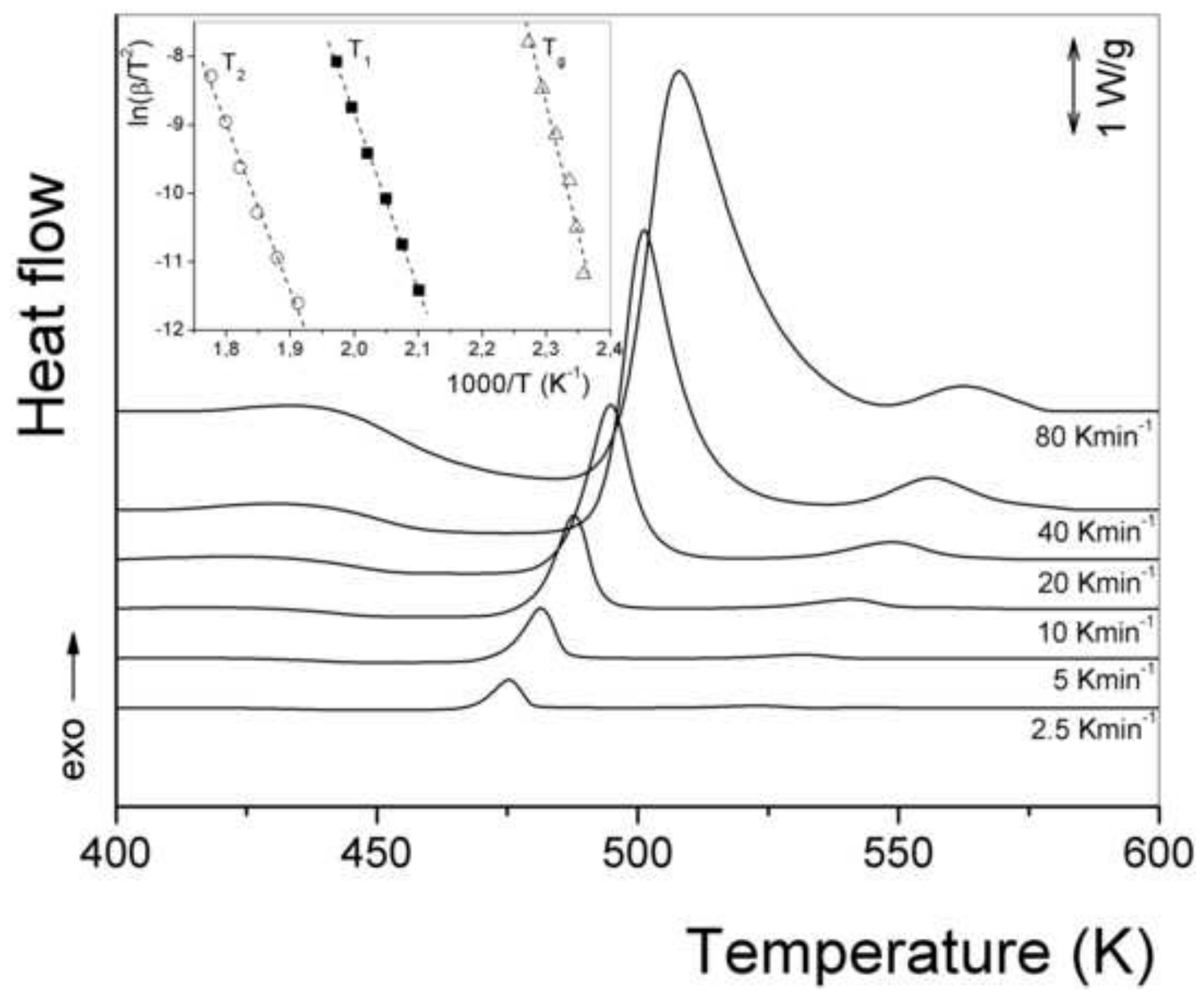




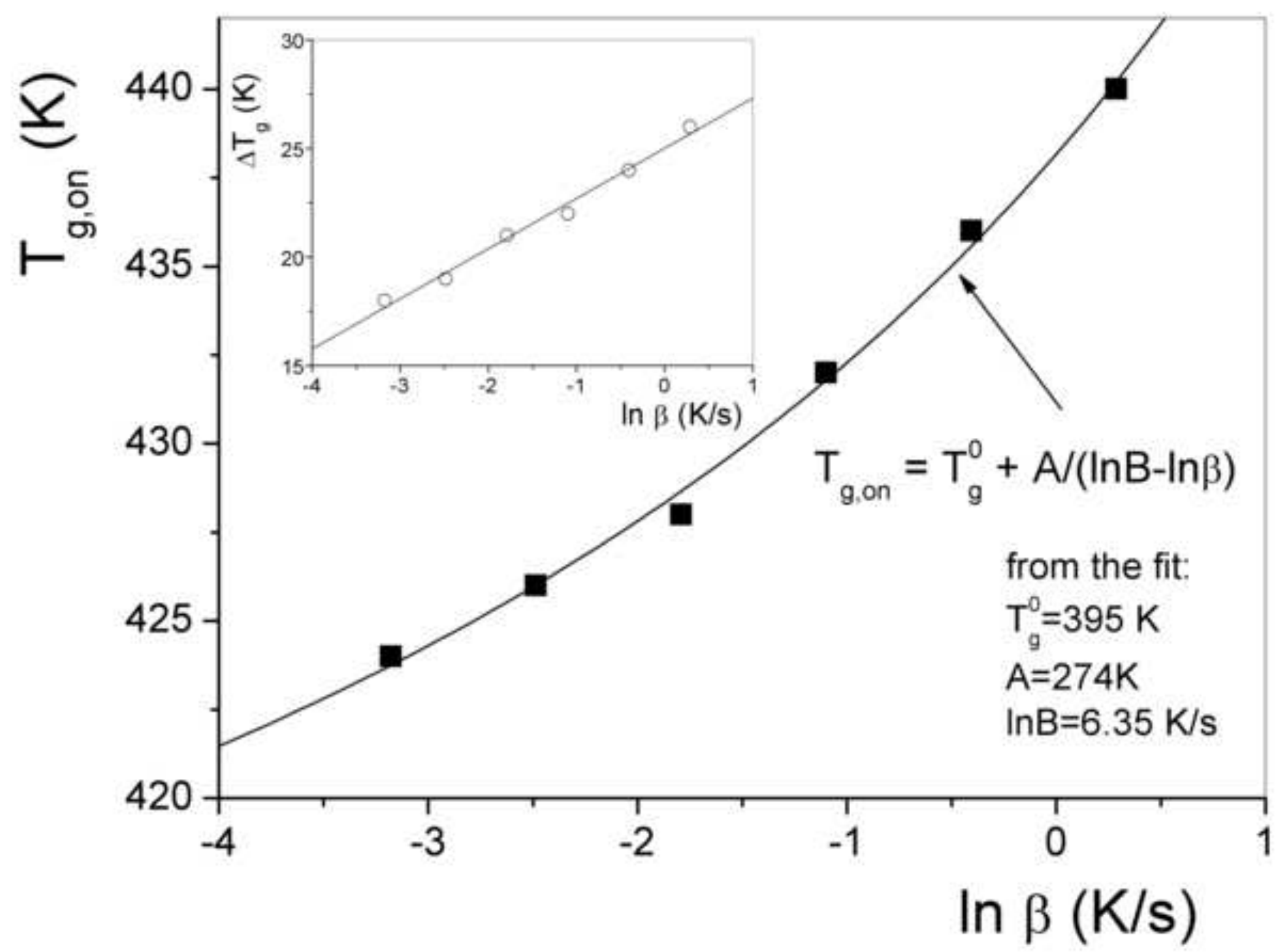




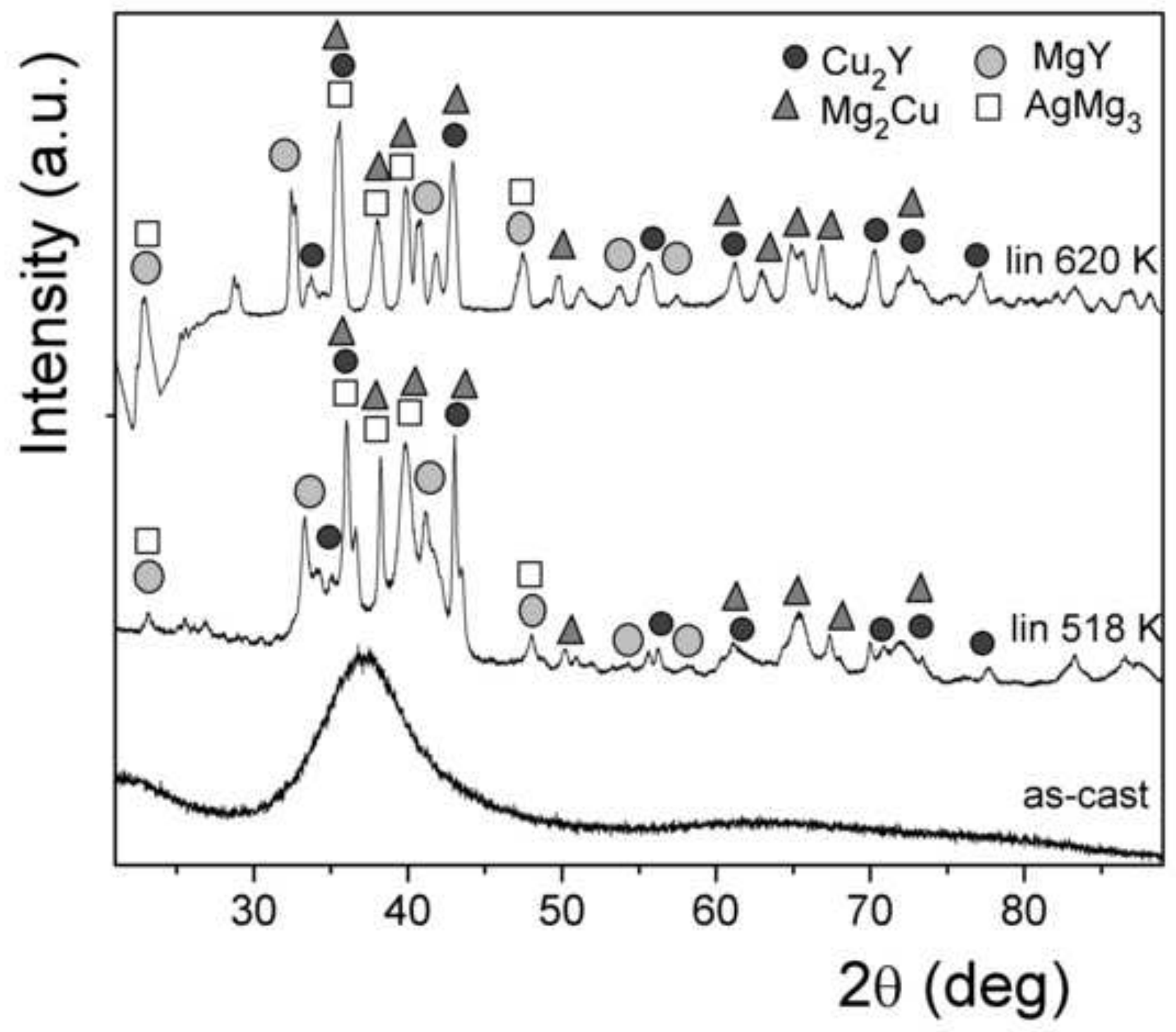


Click here to download high resolution image

International Journal of Hydrogen Energy 39 (2014) 9230-9240 


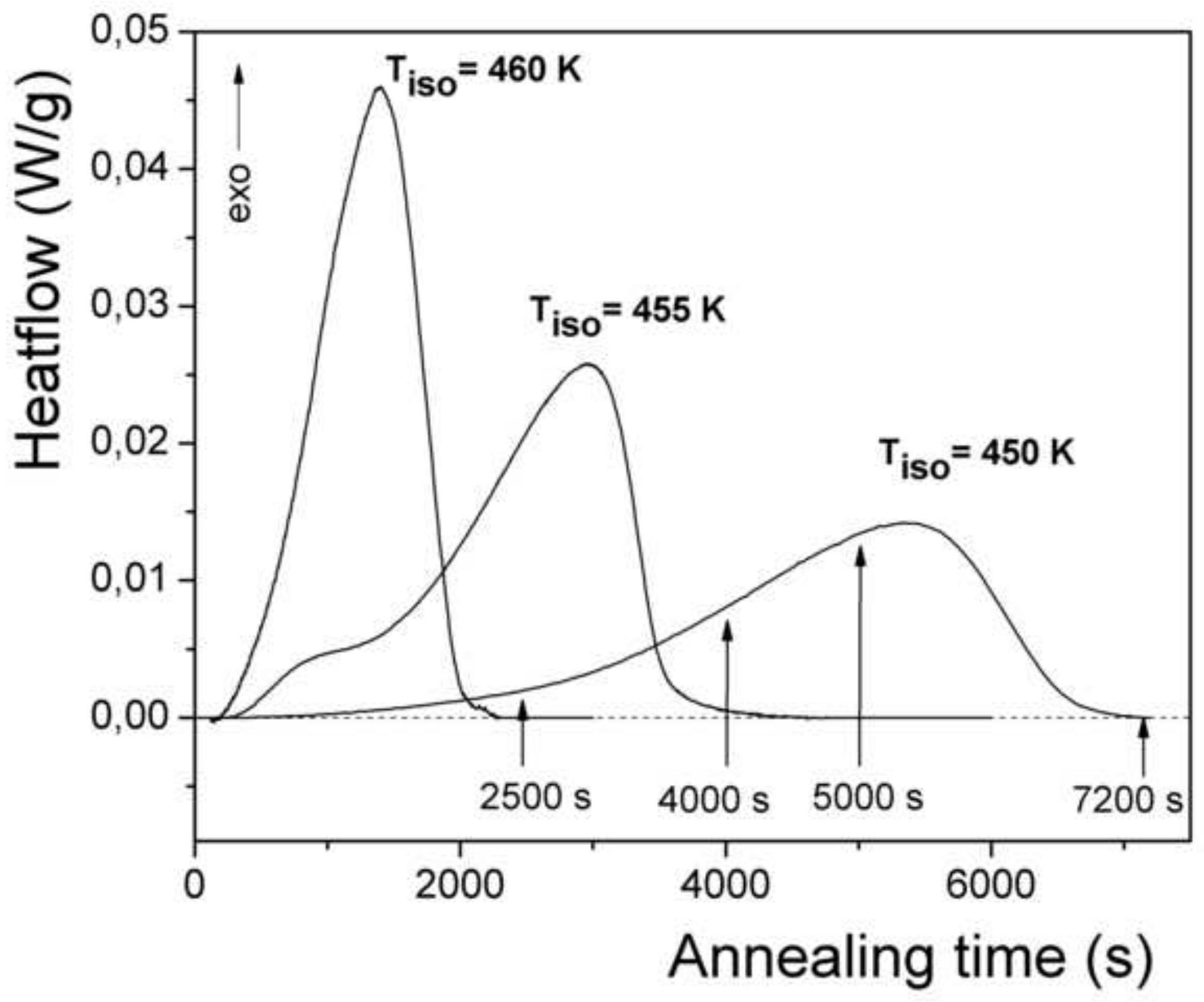


Click here to download high resolution image

International Journal of Hydrogen Energy 39 (2014) 9230-9240

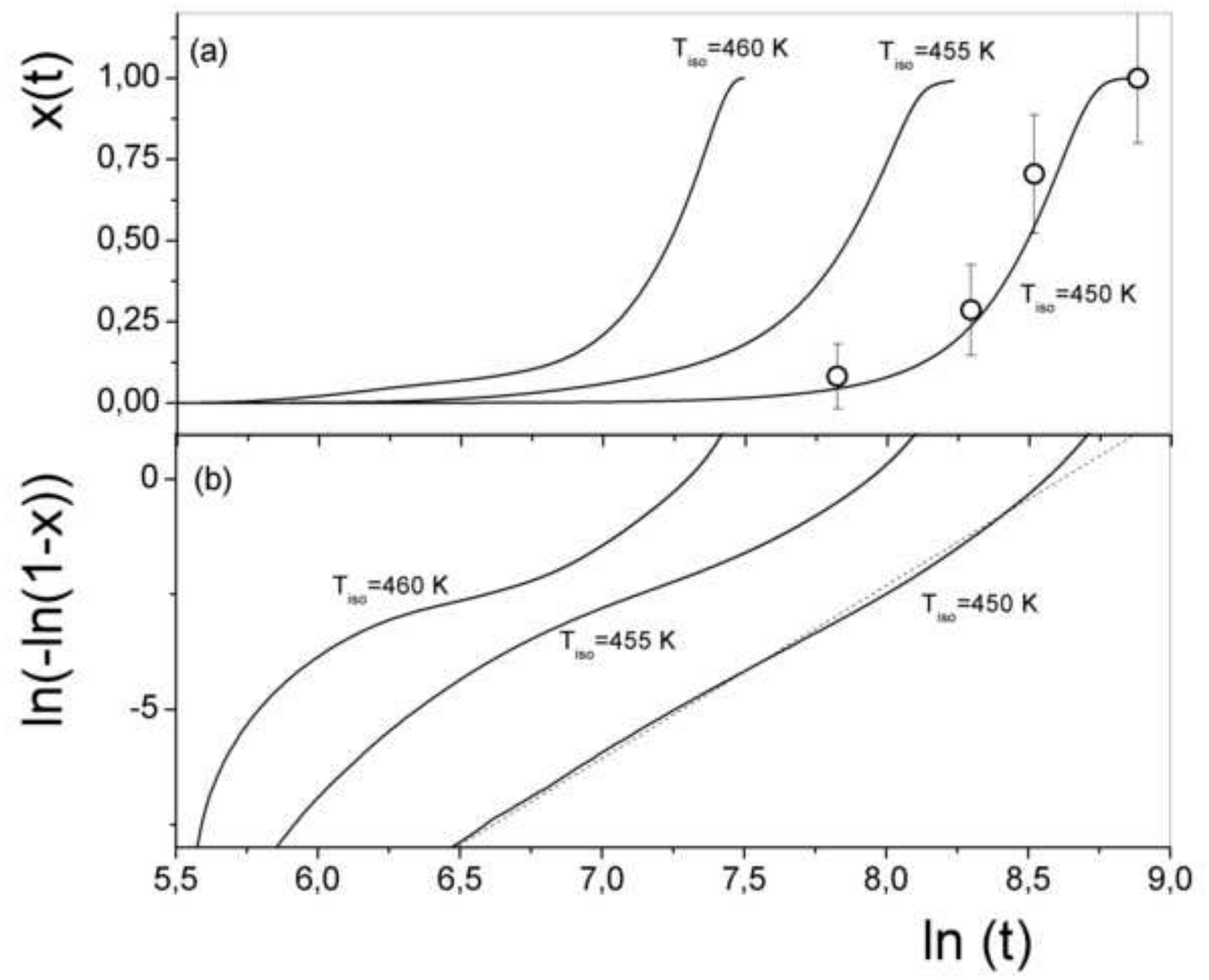




\section{igure8}

Click here to download high resolution image

International Journal of Hydrogen Energy 39 (2014) 9230-9240

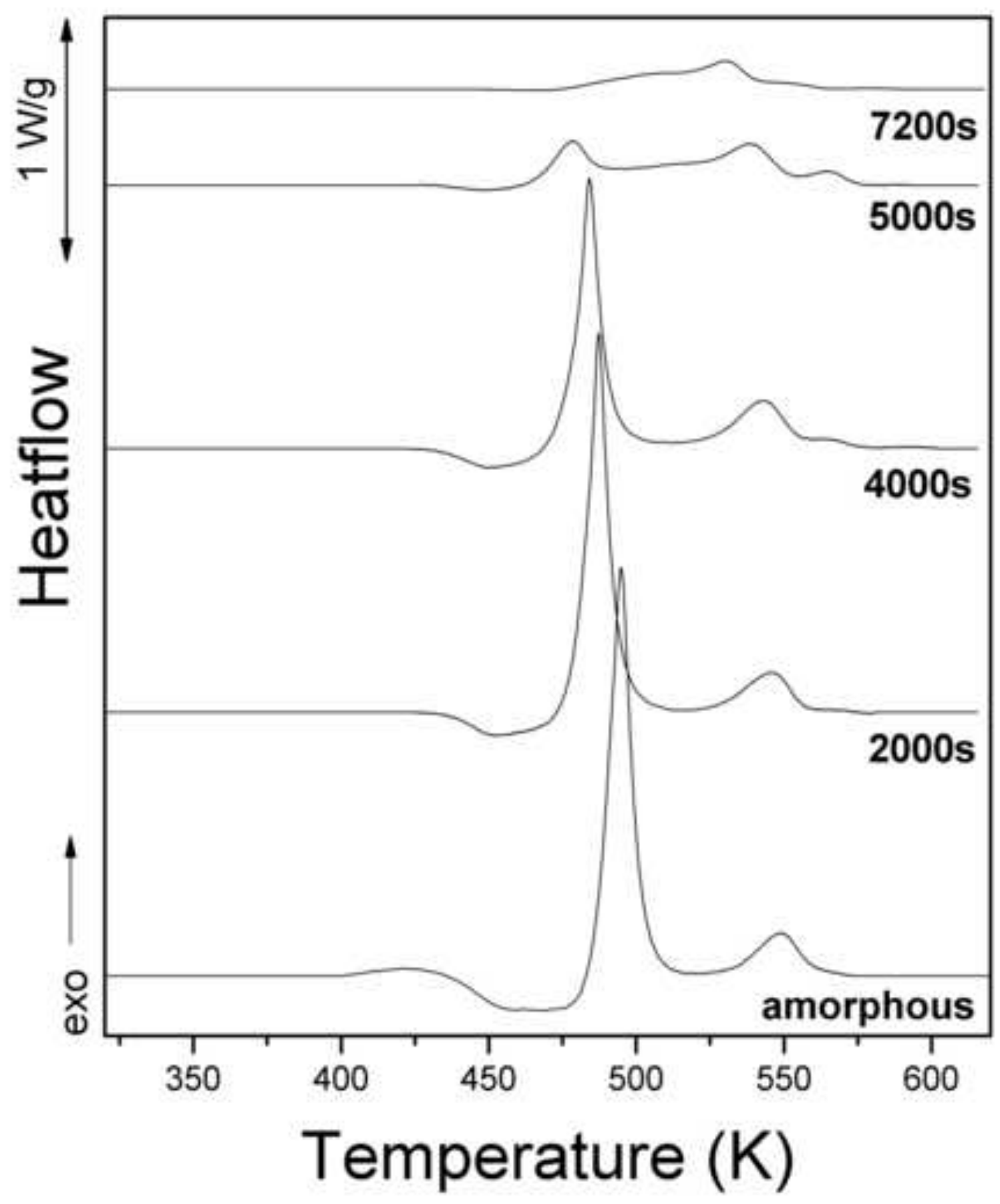




\section{igure}

Click here to download high resolution image

International Journal of Hydrogen Energy 39 (2014) 9230-9240

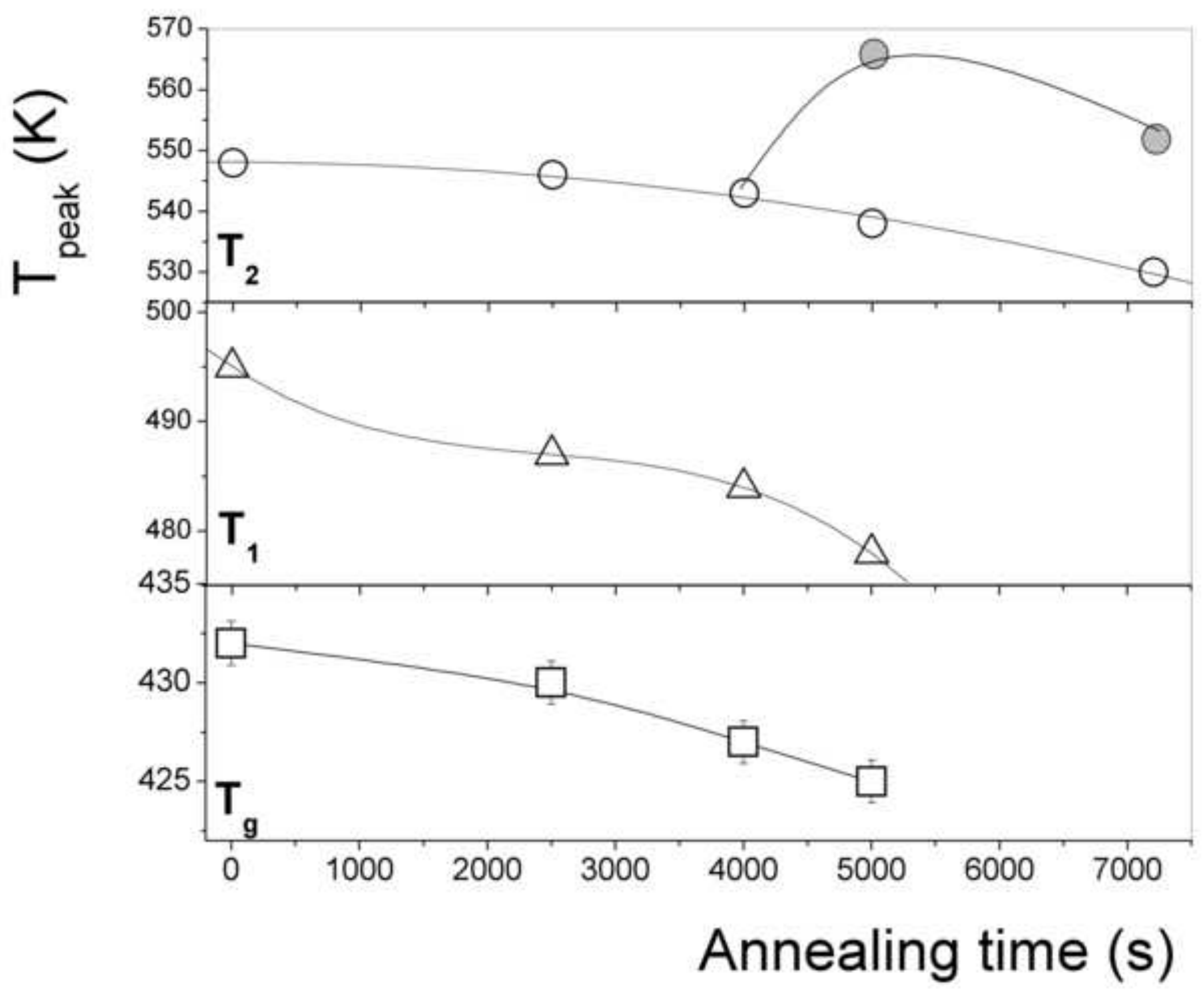




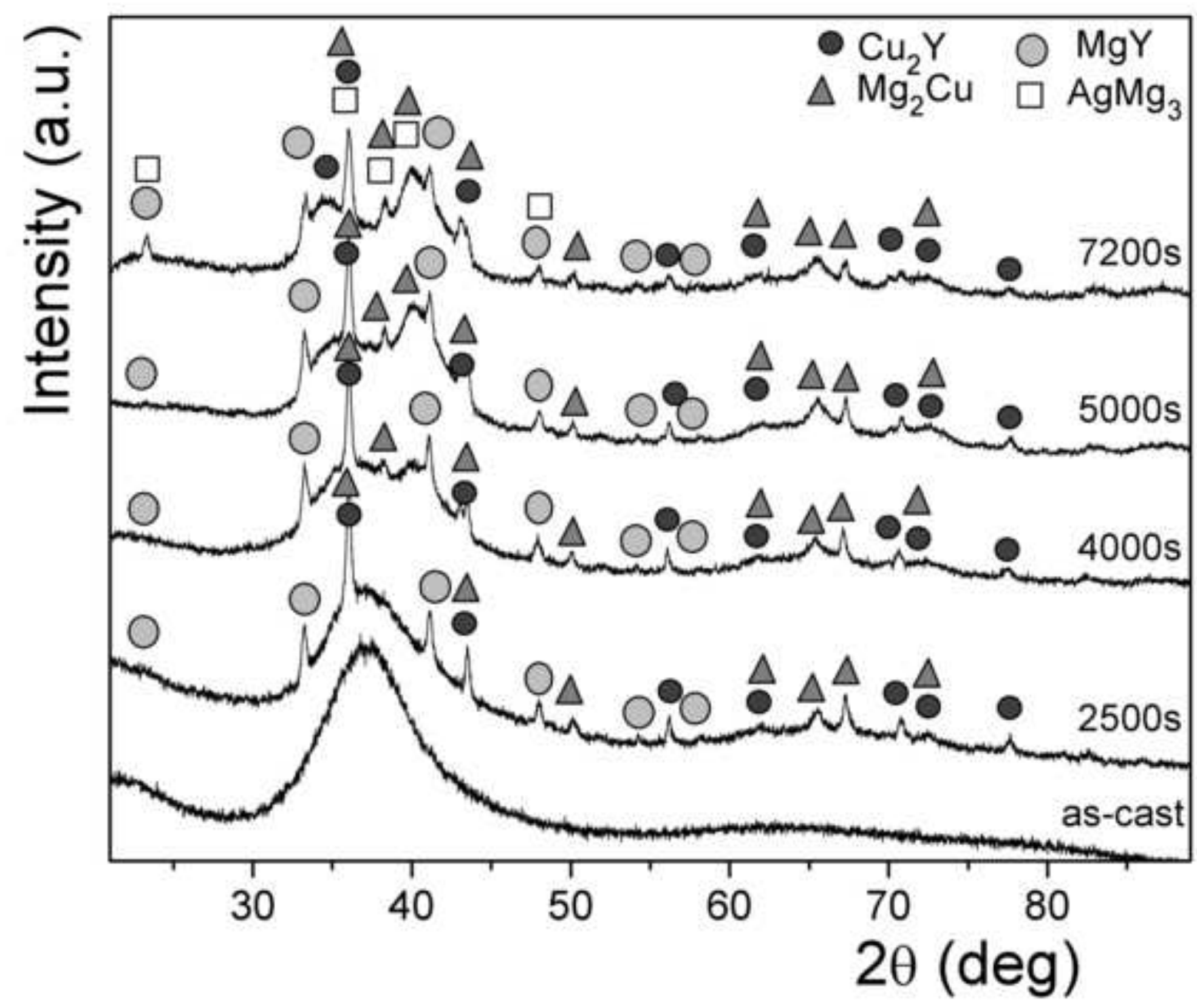




\section{Click here to download high resolution image}

International Journal of Hydrogen Energy 39 (2014) 9230-9240

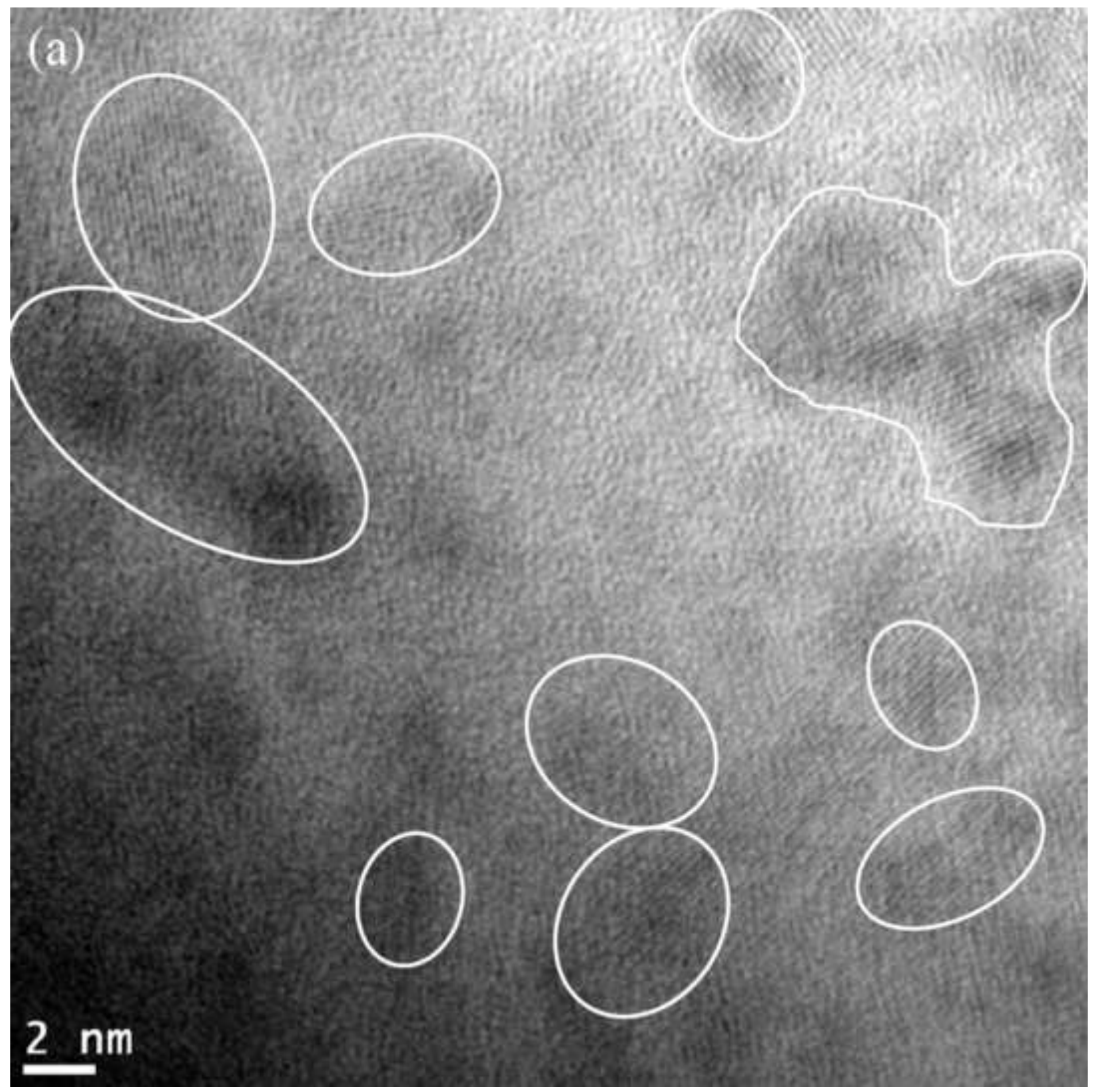


Click here to download high resolution image

International Journal of Hydrogen Energy 39 (2014) 9230-9240

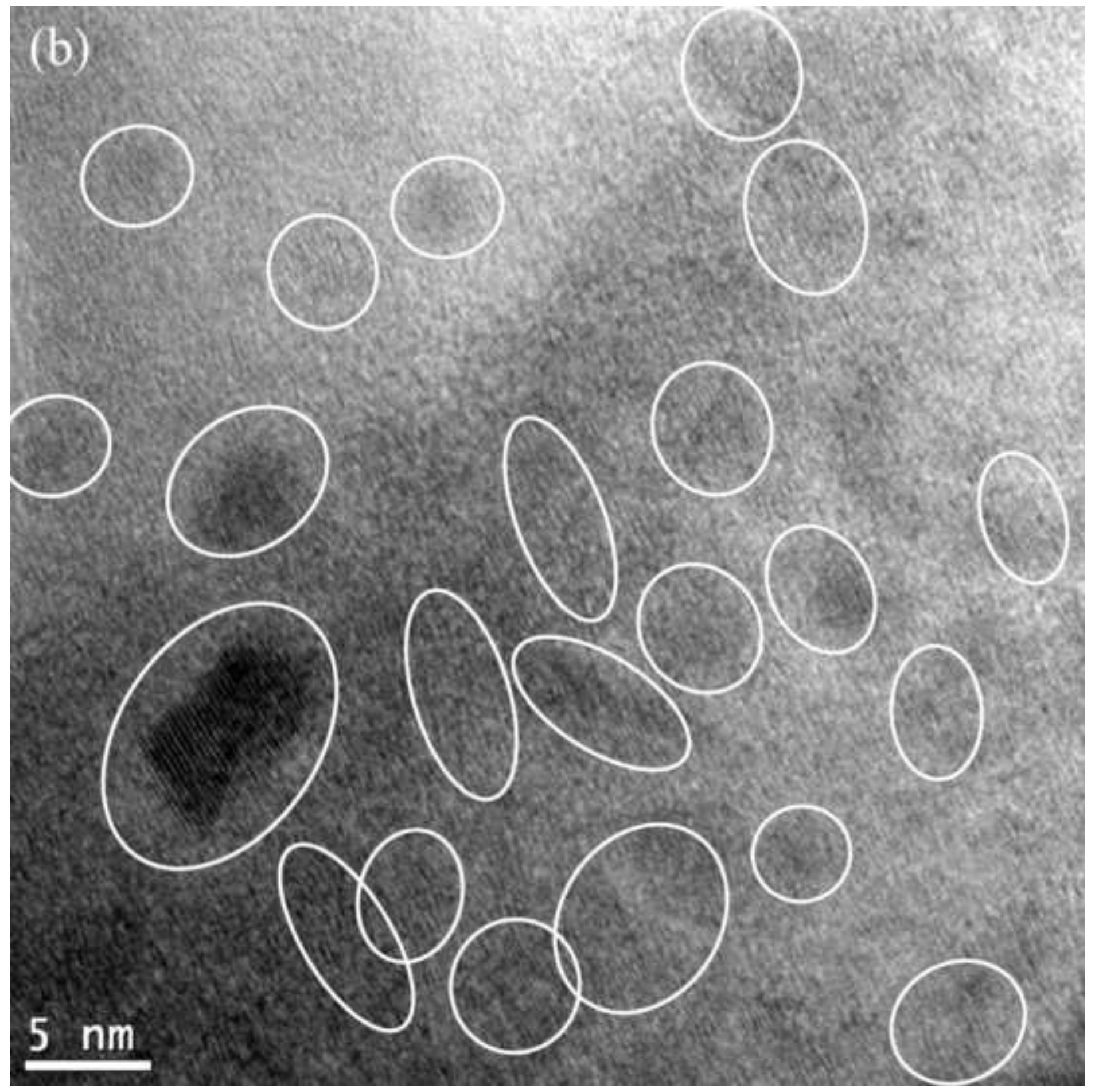




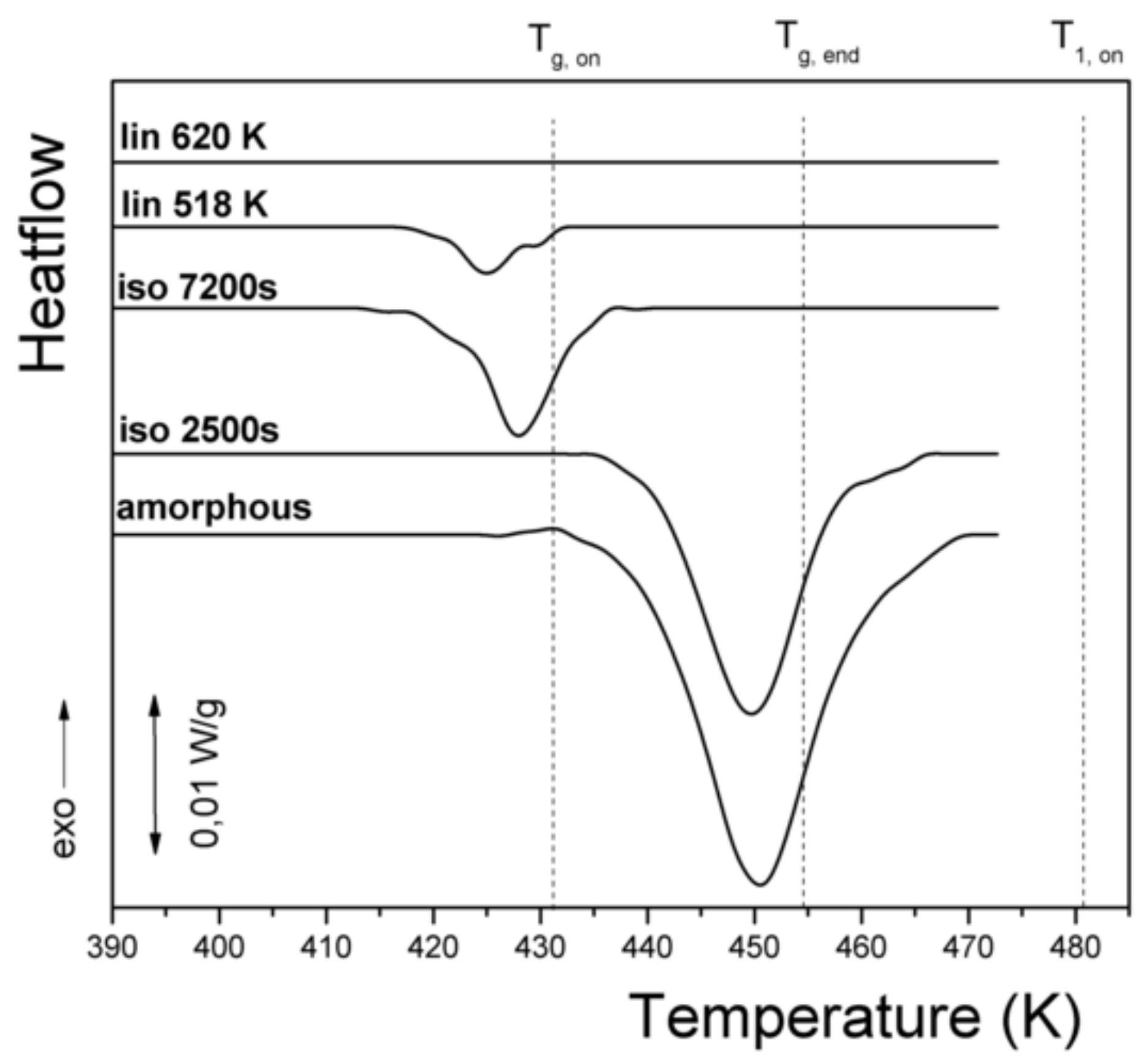

